\title{
Male involvement in family planning: A challenge for the national programme workshop
}

National Institute of Population Research and Training

Deutsche Gesellschaft Fur Technische Zusammenarbeit (GTZ)

Population Council

AVSC International

Follow this and additional works at: https://knowledgecommons.popcouncil.org/departments_sbsr-rh

Part of the Communication Commons, Family, Life Course, and Society Commons, and the International Public Health Commons

How does access to this work benefit you? Let us know!

\section{Recommended Citation}

National Institute of Population Research and Training, Deutsche Gesellschaft Fur Technische Zusammenarbeit (GTZ), Population Council, and AVSC International. 1996. "Male involvement in family planning: A challenge for the national programme workshop," workshops. Dhaka: Population Council. 


\title{
MALE INVOLVEMENT IN FAMILY PLANNING: A CHALlENGE FOR THE NATIONAL PROGRAMME WORKSHOP
}

\author{
FINAL REPORT
}

National Institute of Population Research and Training (NIPORT)

Deutsche Gesellschaft Für Technische Zusammenarbeit (GTZ)

The Population Council

AVSC International

This project was supported by the Population Council's Asia and the Near East Operations Research and Technical Assistance (ANE OR/TA) Project. The ANE OR/TA Project is funded by the US Agency for International Development, Office of Population, under Contract No.DPE-3030-C00-0022-00, Strategies for Improving Family Planning Service Delivery. 


\section{TABLE OF CONTENTS}

Page

Foreword

Executive Summary

ii-iii

I. Introduction

II. Objectives

III. Implementation of the Seminar 2

- Inauguration 3

- $\quad$ Open discussion 5

IV. Group Recommendations 9

$\begin{array}{ll}\text { V. Concluding Session } & 21\end{array}$

$\begin{array}{ll}\text { VI. Seminar Evaluation } & 24\end{array}$

$\begin{array}{ll}\text { VII. Seminar Schedules } & 27\end{array}$

VIII. List of Participants $\quad 28$

IX. Seminar Papers

Male Involvement in Family Planning Programme: Bangladesh 33

Role of Male as the User of Contraceptive Methods 44

Males as FP-MCH-RH Service Providers 52

Highlights of Regional Male Involvement in Family Planning Programmes 63

Male Motivation for Promotion of Women's Participation in Decision 78 Making - An Important Element of Family Planning Programme 


\section{Director General National Institute of Population Research and Training (NIPORT) Ministry of Health and Family Planning}

\section{FOREWORD}

The workshop on " Male Involvement in Family Planning: A challenge for the National Programme" was held in Dhaka, on June 25-26, 1996. It is organized by NIPORT, with the technical and financial assistance from GTZ, AVSC International, Pathfinder International and the Population Council. During the period 1983-93, Bangladesh has made remarkable achievements in Family Planning, but the involvement of males in family planning has been proved to be insignificant. It is urgent to spread messages and to make males aware of their roles and responsibilities for effective participation in FP-MCH program.

The deliberations and discussions at the workshop has brought many ideas and specific recommendations. Moreover, the workshop has provided an opportunity to the policy makers, programme managers, researchers, development partners and donors to share their experiences.

I am thankful to Dr. Heide Richter, Team Leader, GTZ, Dr. A. J. Faisel, Country Representative, AVSC International, Dr. Ubaidur Rob, Resident Adviser, Population Council, for their assistance and advice. I am also thankful to the Directorate of Family Planning and the Directorate of Health Services for their support and cooperation. Over and above, I am thankful to the distinguished participants for their active participation and deliberations in the workshop.

I am also thankful to Research Unit of NIPORT specially to Dr. Ahmed Al Sabir, Director (Research) in particular for their hard work to organize the workshop.

I am sure the recommendations and guidelines that have evolved through this workshop will help us in developing strategies and make specific programme interventions in this important aspect of National Family Planning Programme.

A.K.M. Rafiquz Zaman

\section{EXECUTIVE SUMMARY}

Bangladesh family planning programme has achieved remarkable success in reducing fertility during the past decades. But male involvement in family planning is lagging behind. Increasing the 
involvement of men in family planning programme is a challenge. A two-day seminar on "Male Involvement in Family Planning: A Challenge for the National Programme" was jointly organized by NIPORT, with technical and financial assistance from GTZ, AVSC International, and the Population Council. The objectives of the seminar were to review the research findings on methods currently used, determine male involvement policy, strategy and formulate action plan for male involvement including IEC, counselling and programmatic interventions. About 120 participants from Government, Non-Government, private organizations and donor agencies attended the seminar. The participants were joined by resource persons from ICDDR,B, BRAC, Directorate of Family Planning and the Population Council.

The seminar was held in Dhaka during on June 25-26, 1996. The inaugural session of the seminar was chaired by Mr. Khan Amir Ali, Additional Secretary, Ministry of Health and Family Welfare. The guests of honour Professor A. K. Shamasuddin Siddiquey, Director General, Directorate of Health Services, Mr. Shirajul Islam and Mr. Akhtaruzzaman Khan, Joint Secretaries, Ministry of Health and Family Welfare (MOHFW), Mr. Khairuzzaman Chowdhury, Director General, Directorate of Family Planning, and Mr. A. K. M. Rafiquz Zaman, Director General, NIPORT spoke on the occasion. The guests in their speeches emphasised the need for more involvement of men in family planning and the prevailing misconceptions about male contraception, specially vasectomy, that should be addressed with proper IEC programmes.

After the opening remarks, five papers were presented by researchers/programme managers of the AVSC International, Directorate of Family Planning, Population Council, PIACT, NIPORT/GTZ and Pathfinder International. The papers were as follows:

- Male Involvement in Family Planning Programme: Bangladesh

- Role of Male as the User of Contraceptive Methods

- $\quad$ Males as FP-MCH-RH Service Providers

- Highlights of Regional Male Involvement in Family planning Programmes

- Male Motivation for Promotion of Women's Participation in Decision Making- An important Element of Family Planning Programme

The presentation of papers was followed by group discussions. The participants were divided into five groups who discussed five crucial issues related to male participation in family planning. The participants felt that for increasing male participation in family planning there should be some action to marginalize socio-cultural constraints, ensure the availability of service facilities to cater male needs, arrange training of service providers, undertake innovative research and extend coverage of male issues in IEC activities.

The seminar concluded on June 26, 1996. Mr. Mohammad Ali, Secretary, MOHFW, chaired the concluding session. The guests of honour who spoke on the session were Mr. Khairuzzaman Chowdhury, Director General, Directorate of Family Planning, Mr. A. K. M. Rafiquz Zaman, Director General, NIPORT. In his concluding remarks, Mr. Mohammad

Ali, Secretary, MOHFW hoped to have programmatic activities generated on the basis of the 
recommendations of the seminar. He suggested to organize another seminar after six months to review the concrete steps taken meanwhile to increase male participation in any significant way.

The following summary recommendations were provided by the groups.

- $\quad$ Equal emphasis should be laid on male and female in policy formulation, program development and implementation regarding: community mobilization, IEC, training, and service delivery.

- Method specific (Condom and Vasectomy) messages should be broadcast through radio and TV. The advantages and benefits of male participation in family planning should be highlighted in advertisements/publications. Advocacy of vasectomy through prominent personalities in mass medias (leaflets, posters etc) should be taken up.

- Messages on male involvement in family planning should be integrated in the training sessions of the GO/NGO service providers and school curricula.

- Group discussions with village leaders, religious leaders and prospective users should be organized.

- The job description of male workers (FPIs, HAs, MAs) should be redefined to enhance contact with eligible males in order to dispense combined health services.

- The service delivery hours of the clinics should be rescheduled in keeping with the availability of the males.

- The private sector and local bodies should be involved in program implementation and the private medical practitioners should be allowed to play a more active role to promote male involvement.

- Method-specific (Vasectomy and Condom) training and counselling materials should be developed for the service providers.

- The thana level service providers should be trained on non-scalpel vasectomy and their refresher training should be designed for them on male methods.

- The parliamentarians, policy makers and program managers are needed to be sensitized on the issue of involvement of male in reproductive health.

- The overall service delivery situation should be reviewed to ascertain the current state of male participation in the family planning programme.

- The reasons for decline in vasectomy performance are needed to be examined in greater details.

\section{INTRODUCTION}

Male involvement in family planning is not a new concept. Active participation of males as the user 
of family planning methods such as, vasectomy, condoms and the traditional methods like periodic abstinence and withdrawal, as well as their supportive role in contraception of women are necessary in carrying out successful MCH-FP programmes. In case of traditional methods, particularly abstinence and withdrawal, male involvement is required for their successful use. According to the Bangladesh Demographic and Health Survey the current contraceptive use rate is 45 percent where the use of male methods is only 11 percent, one quarter of all users. Among the male methods, condoms are being used by three percent and the traditional methods are being used by eight percent of the current users.

In the early decades of Bangladesh Family Planning Programme, men actively participated in accepting vasectomy and thousands did so. About two percent of the couples were protected by vasectomy. Now, the acceptance of vasectomy has declined sharply. Indeed the number of vasectomies has dropped to less than 1000 in a current month, from 25,000 in 1984.

Less involvement of male in family planning does not necessarily mean that men are reluctant to use contraceptive methods. Rather, the male need for family planning is neglected by the family planning programme and its service providers. Males have no ready access to the family planning information necessary to make decision nor can they find service facilities which will cater to their needs. As a result, they cannot make informed choice for accepting family planning methods nor can they take an active part in supporting their wives decision to use a family planning method, while their attitudes indicate that they may be willing to involve themselves in family planning if the programme addresses them properly.

In addition, the challenge for the national family planning programme of Bangladesh is to maintain and continue its remarkable success. Great progress has been made but a greater progress must be made in the future if the replacement level of fertility is to be achieved by the year 2005. This challenge cannot be met without the active participation of men in the programme, both as family planning method users and as supportive partners.

\section{OBJECTIVES}

The seminar on "Male Involvement in Family Planning: A Challenge for the National Programme" was organized with an aim to facilitate the sharing of experiences of the programme managers, policy makers and researchers in the success and failure of male involvement in family planning in order to determine the policy and implementation strategy of increased male involvement in the family planning programme.

The specific objectives of the seminar were to:

- review the research findings on methods currently used, future preference for use, as well as attitudinal information regarding male involvement in family planning

- $\quad$ provide information about successful male involvement programmes implemented in Bangladesh and the neighbouring countries

- determine policy and strategy of male involvement to be followed by the national 
programme and

- formulate programs for male involvement, including IEC counselling and programmatic interventions.

\section{IMPLEMENTATION OF THE SEMINAR}

This was a two-day seminar held on June 25-26, 1996. The business session of the seminar was divided into three parts: paper presentation, group discussions, plenary and open discussion. The inaugural session was followed by presentation of papers. The following five papers were presented in the seminar:

- Male Involvement in Family Planning Programme: Bangladesh

- Role of Male as the User of Contraceptive Methods

- $\quad$ Males as FP-MCH-RH Service Providers

- Highlights of Regional Male Involvement in Family planning Programmes

- Male Motivation for Promotion of Women's Participation in Decision Making- An important Element of Family Planning Programme

The participants were divided into five different groups to discuss important topics related to male involvement in family planning. The topics of the group discussions were:

Group 1: $\quad$ Social and Cultural Issues Related to Male Involvement in FP Program

Group 2: $\quad$ FP-MCH Service Delivery Issues in Promoting Male Involvement

Group 3: $\quad$ Training Needs for Service Providers

Group 4: Potential Areas for Future Research on Male Participation/Innovative Programmatic Interventions

Group 5: Community Participation and IEC to Increase Male Involvement

Each group consisted of 10-15 participants, had a facilitator and a rapporteur, and was provided with a guideline related to the group-specific topics. The group members were advised to discuss about programme implications along with the recommendations for future development. However, the output of the group discussions was presented in the next session for plenary as well as in the open discussions where these were reviewed by the participants. Afterwards, one representative from each group together finalised the recommendations based on the suggestions which emerged from the open discussions. 


\section{Inauguration}

The inaugural session of the seminar started at 9:00 am on Tuesday, June 25, 1996, at a local hotel in Dhaka. Mr. Khan Amir Ali, Additional Secretary of the Ministry of Health and Family Welfare (MOHFW) chaired the session. The guests of honour Professor A. K. Shamsuddin Siddiquey, Director General, Directorate of Health Services, Mr. Shirajul Islam, and Mr. Akhtaruzzaman Khan, Joint Secretaries, Ministry of Health and Family Welfare, Mr. Khairuzzaman Chowdhury, Director General, Directorate of Family Planning and Mr. A. K. M. Rafiquz Zaman, Director General, NIPORT attended and spoke on the occasion.

The inaugural session of the seminar started with the welcome address delivered by Dr. Ahmed AlSabir, Director (Research), NIPORT. In his welcome address Dr. Sabir stated that though this programme had evolved over the years through various phases much more could be done in this respect. In recent years, organizations and experts in the field of population and reproductive health had recognized the need for more involvement of men in the programme. He hoped that the seminar would enable us to share feelings and experiences on male involvement in family planning and help us in designing and setting future strategies. He mentioned that NIPORT had organized this sort of theme-based seminar involving different leading organizations of this country for the first time. This attempt would help foster research activities for the benefit of the country. Dr. Sabir hoped that the participants of the seminar would freely discuss the different issues and provide a guideline with ultimate objective of the reduction of fertility.

Mr. A. K. M. Rafiquz Zaman, Director General, NIPORT gave a brief background of the seminar. Mr. Zaman stated that the overall aim of Bangladesh family planning programme was to raise CPR to 75 percent and reduce TFR 2.1 which was not possible to be achieved without male involvement in family planning. He referred to the recommendations of several national level seminars which had recommended for increased participation of male in family planning. Mr. Zaman said that the male participation was considered to be important mainly for three areas - responsible parenthood with increased male role, male motivation and use of male methods. He observed that the seminar had made an avenue to review research findings on the male methods currently used, future preferences for use as well as attitudinal information regarding male involvement in family planning and the successful male involvement programmes in action in Bangladesh and neighbouring countries to determine policy and strategy for increased male involvement. The DG (NIPORT) reiterated that it was an opportunity for those who were involved in policy making, programme management and providing services to share their experiences for better performance in future, particularly on ways and means of making males more effective to do a good job for the national Programme.

Mr. Khairuzzaman Chowdhury, Director General, Directorate of Family Planning, in his speech pointed out that there were some obvious reasons for less involvement of males in family planning. He wished that this seminar would come up with some concrete and workable suggestions that could be applicable in the programme to increase more male participation.

Mr. Md. Akhteruzzaman Khan, Joint Secretary, Ministry of Health and Family Welfare, in his speech said that the family planning programme started in the country within a government framework in 1965. At the beginning of the programme, a large number of vasectomies were performed. Over time it has decreased and was replaced by female sterilization. The underlying 
reason was the lack of training of the field workers in this regard. Though male field workers were recruited they were not trained properly and there was no provision for refresher trainings. In addition to that the IEC activities particularly the inter-personal communication and mass media like radio and television did not give enough coverage to male methods and male motivation. He stressed the need to identify the measures for effective motivation of our male members so that they could accept male methods. He also mentioned that there were male family planning service providers and SMC's service out-lets like pan shops, grocery shops, etc. could be utilised to deliver IEC messages for male motivation. Referring to the success of male involvement in countries like Australia, New Zealand and North America, Mr. Khan observed that we could learn from their experience and achievement and adapt them to make our programme successful.

Mr. Md. Shirajul Islam, Joint Secretary, Ministry of Health and Family Welfare said that male as a user of contraceptive was constrained as male methods were fewer but the supportive role of male was very important. Regarding vasectomy, he said that there were many misconceptions and misunderstanding in the community. Mr. Islam said that it was a common belief that a man having undergone vasectomy would have less sexual power, would become weak and would not be able undertake heavy work. This kind of misconceptions should be uprooted by the service providers.

Professor A. K. Shamsuddin Siddiquey, Director General, Directorate of Health Services, in his speech said that male contraception was a difficult and complicated process but we would be successful if we could gear up the family planning programme with the appropriate male methods which they could accept easily. He said that condom is a very effective method, but withdrawal and periodic abstinence are not hundred percent effective. If a male wished he could have the procedure of recanalization, he observed. Mr. Siddiquey added that these were fraught with problems. However it was necessary that knowledge in this regard should be propagated for increased awareness.

Mr. Khan Amir Ali, Additional Secretary, Ministry of Health and Family Welfare, in his speech said that reduction of high fertility and population growth was a priority concern of development in our country. Over the last two decades fertility decreased due to steady increase in contraceptive use. The findings from 1993-94 BDHS suggest that fertility levels had declined to a half and the use of contraceptive methods had increased almost six fold since 1975. Among 45 percent of current users, 11 percent were using exclusively male methods, which were not comparable to world wide figures. Further quoting 1993-94 BDHS findings he said that male attitude towards small family norm was positive but although only less than two percent were protected by vasectomy and three percent by condoms. Mr. Ali suggested that the underlying causes should be looked into and the strategies and programmatic activities should be developed to increase male involvement in the family planning. He further stated that the Bangladesh family planning programme was also looking for various innovative ways for a big push to reach the replacement level fertility by the year 2005 and the seminar was being organized to examine a very important aspect. The Additional Secretary hoped that the seminar would be able to come up with some recommendations for formulating programme and developing strategies for more involvement of males in family planning.

\section{Open Discussion}


Open discussions were held on the second day of the seminar. The discussions were held after the presentation of the group recommendations. In this session, the participants asked questions, requested for elaboration or added several suggestions to the group recommendations. On behalf of the group, the group leader or the rapporteur answered the questions. Mr. A. K. M. Rafiquz Zaman, Director General, NIPORT presided over the open discussion session.

\section{Discussion on the recommendations of Group: 1}

Dr. Sayeed Jahangeer Haider noted that most of the decisions were taken by males conventionally. But he posed the question whether the males were very proactive in decision making in use of methods of family planning. He however expressed his opinion that they were unconcerned in that matter which had made the issue more complicated.

Dr. Barket-e-Khuda observed that recommendation about strengthening community mobilization or multi-sectoral project were vague. He commented that those were very generalized recommendations.

Dr. Salauddin Ahmed, referring to one of the recommendations of the group calling for involvement of the opponents of family planning in the programme itself expressed his concern that if the opposed were involved it would harm the programme.

In this context Mr. Tofayel Ahmed asked if there was still opposition or vested group in the community.

Mrs. Mufaweza Khan pointed out that our society being a male dominating one, the women were economically dependent on the males which prompted them to protect their husbands health always. She enquired whether such values could be corrected through appropriate programmatic measures.

Dr. Ahmad Neaz, group leader as well as the presenter of the group recommendations answered the questions on behalf of the group. Citing examples from the study that was undertaken by his associates three years ago, he said that there were certain cases where the husbands had not opposed their wives to accept family planning but there were opposition in many cases. Referring to the findings of other studies, he said that there were non-users who tried to adopt family planning but could not accept for the fear of side-effects or objection from husbands and in-laws.

Dr. Neaz stated that about six percent of the contraceptive users were using family planning methods despite the objection of their husbands. He said that community mobilization or multisectoral approach for male involvement in family planning was already in the programme strategy but it was not practiced. He stressed the need for holding of union or thana committee meeting. He also mentioned that the opponents of family planning were very much active in the past and their numbers had now come down. He added that FPAB had provided training to several thousand Imams of mosques who were no longer antagonists. He said that there were still opposition from vested groups particularly in Sylhet and Chittagong regions. Dr. Neaz suggested that values and norms on the part of males use of contraceptive were lacking because of exclusive target of female in the programme which should be changed to involve male in the family planning activities. 


\section{Discussions on the Recommendations of Group: 2}

Mr. Tofayel Ahmed asked for clarification about the recommendations for clinical service delivery to render vasectomy service. He said that the service of FWC was only for the females while males could also avail the services. Mr. Ahmed expressed his opinion that the males were not coming to the FWC to avail of the services due to motivational or other problems.

Mr. Faruque Ahmed stated that ways and means should be found out to effectively involve the private sector in increasing male participation in family planning. In this context the involvement of the local government in the family planning had become important, he added. He also wanted to know whether the group members were aware that the female workers were addressing the male partners exclusively in the pilot areas like Gonoshastha Kendra (GK).

Dr. Syed Jahangeer Haider said that there were service points being operated exclusively on gender concern meaning that the FWCs were only for females while MAs were also found to be working in FWCs providing services to male. He suggested that the FWCs could be opened at different hours to render services for males. Dr. Haider doubted that a private sector clinic could ever be run on gender consideration.

Dr. A. J. Faisel admitted that the recommendation dwelt mostly on the NGOs and public sector and no specific recommendation was put up with regard to the private sector. He said that local government institutions should be made more active, and be given more responsibility in overseeing the service delivery issue. The implementation of the recommendation would need more in-depth discussion. Dr. Faisel said that there were some clinics for example Kumudini Hospital which encourage both husband and wife come together. He however expressed his ignorance about any research having been done in this field.

\section{Discussion on the Recommendations of Group: 3}

Mr. Habibur Rahman suggested for utilising the existing training facilities rather than developing new training institutions to reduce backlog in training.

Dr. Sayeed Jahangeer Haider said that there was a recommendation for developing paramedic cadres for IUD services. In this context he suggested that paramedic cadre for vasectomy services could be developed and the Medical Assistant could be trained to perform vasectomy.

Dr. Barkat-e-Khuda said that there was considerable training backlog in the family planning sector that indicated the need for strengthening the training institutions.

Dr. Mizan suggested to increase male contact by the female workers who were needed to be motivated through training and orientation.

Dr. S. M. Shahidullah stated that there were a good number of training institutions whose capabilities could be strengthen by building up training components and suit particular training needs. 


\section{Discussions on the Recommendations of Group: 4}

Mr. Yusuf Chowdhury said that the sustainability and cost-effectiveness of the programme had conventionally been looked at from the angle of the public sector while the private sector with its organized groups and resources had not been properly assessed. He suggested that the private medical practitioners could be used for clinical contraception.

Dr. Barket-e-Khuda said that a long list of research agenda had been proposed by the group. He suggested to prioritize them keeping three issues in mind: (1) management issues (2) quality of care (3) sustainaibility.

Dr. Syed Jahangeer Haider suggested that the group had covered almost all the issues except the relationship with the cultural process, and intensive study, either of qualitative or anthropological nature, of which should be done involving universities or institutes.

Dr. S. Majid mentioned that efforts were made to work out short, implementable, and workable suggestions. In doing so they had to prioritize certain issues, and consider their cost-effectiveness. He also stated that research areas had been identified to conceptualize male participation. Dr. Majid mentioned that the cost-effectiveness in research could be done in family planning sector but in the context of health and family planning sector this particular methodology was not worth recommending.

\section{Discussions on the Recommendation of Group: 5}

Dr. Barket-e-Khuda said that unless the involvement of the male community members could be ensured in terms of planning and implementation of the various programme activities, ownership in the programme would be lacking. He asked about the mechanism through which this participation would be made effective. He said that the group had recommended for energizing Thana Family Planning Committee and observed that without community participation the suggested energizing of the Union Family Planning Committees would not be accomplished.

Mr. Abu Yusuf Chowdhury said that two types of male contraceptives were available, viz. condom and vasectomy, the later being a terminal method. Thus we were left with only one method. He observed that none had indicated the use effectiveness of condom, which was vital in ensuring male participation. Mr. Chowdhury mentioned that an MR study indicated that one-forth of the clients who came for MR were cases of method failure. If the use of condom was not effective there would not be any improvement in the male involvement as the user of contraceptive, he observed.

Mr. Ahmed-Al-Kabir said that the knowledge on family planning specially about male involvement was very limited among the programme managers like the Deputy Director, Family Planning Officers and below level. He suggested that there should be some specific programme targeted to that issue. Mr. Kabir also indicated that the elected representatives including the members of the parliament could contribute a lot in this regard. 
Dr. Syed Jahangeer Haider stated that the persons providing IEC were service providers, so were the Family Planning Officers. The service providers did not only mean the clinical service providers. Accordingly, the recommendations of the group had covered the issue. However, the involvement of the elected representatives which should be considered. 


\section{GROUP RECOMMENDATIONS}

\section{Group 1}

\section{Social and Cultural Issues Related to Male Involvement in Family Planning Program}

- Male and Female should receive equal focus on policy formulation, program development, and implementation regarding-

- Community mobilization

- IEC

- Training

- Service Delivery

Persons responsible: Secretary $(M O H F W), D G(H), D G(F P), D G(N I P O R T), N G O$

- The role of male workers (FP, Health) to address male involvement in reproductive health should be redefined.

Persons responsible: $D G(H), D G(F P), N G O s$

- Sensitization of policy makers, parliamentarians, program planners, program managers for male involvement in reproductive health.

Persons responsible: $D G(F P), D G(N I P O R T), D G(H)$, Dir (IEM), NGO.

- Strengthening the utilization of existing government, NGO and private facilities to enhance male client provider contact.

Persons responsible: Dir (Clinical Services), $D G(H), N G O$.

- Studies should be conducted in the following areas:

- Utilization of combined service delivery packages

- Client provider interaction on male involvement

- Interspousal communications

- Institutional reimbursement of private sector for male reproductive health services and its effects on utilization of services. 


\section{Group 2}

\section{FP-MCH Service Delivery Issues in Promoting Male Involvement}

\section{Categorization of issues:}

- Management and community support

- Issue related to service provider and worker (GOB and NGO)

- Issues in connection with the use of methods/male's supporting use of all methods

\begin{tabular}{|c|c|}
\hline ISSUES/EXPERIENCES & RECOMMENDATIONS \\
\hline $\begin{array}{l}\text { Clinic and service delivery sites are set up to } \\
\text { serve mostly females. Service delivery } \\
\text { approaches focus more on females. }\end{array}$ & Program design needs to be changed. \\
\hline $\begin{array}{l}\text { Female field workers both in the public and } \\
\text { NGO sectors reach only women. }\end{array}$ & $\begin{array}{l}\text { Female field workers should make all } \\
\text { efforts to contact more males. } \\
\text { Involve the FPIs to contact the } \\
\text { husbands/males. } \\
\text { Involve the husbands of the female field } \\
\text { workers and service providers. }\end{array}$ \\
\hline $\begin{array}{l}\text { Males are either not served or not properly } \\
\text { attended in the satellite clinics. }\end{array}$ & $\begin{array}{l}\text { Policy guidelines needs to be formulated } \\
\text { for serving males in the existing satellite } \\
\text { clinics. } \\
\text { With the help of male Medical Assistants \& } \\
\text { FPIs separate satellite clinics may be } \\
\text { organized for the males only. }\end{array}$ \\
\hline $\begin{array}{l}\text { Male staff at all levels of FP and Health do } \\
\text { not undertake any motivational job. }\end{array}$ & $\begin{array}{l}\text { Change job description of male staff by } \\
\text { including motivational responsibilities. } \\
\text { Activate/assign the male field level FP and } \\
\text { Health staff to reach more males. } \\
\text { The working facilities for male service } \\
\text { providers and field staff need to be } \\
\text { improved. } \\
\text { Improve job security of the male field staff } \\
\text { (FPI) by including them in the revenue } \\
\text { budget. }\end{array}$ \\
\hline No attention is given to male counseling. & Couple counseling/joint counselling sessions \\
\hline
\end{tabular}




\begin{tabular}{|c|c|}
\hline ISSUES/EXPERIENCES & RECOMMENDATIONS \\
\hline & $\begin{array}{l}\text { may be promoted. This can be done by } \\
\text { either male or female service providers. } \\
\text { Explain to the husbands the reasons for side } \\
\text { effects and all about the importance of } \\
\text { different services provided for females } \\
\text { including the MCH ones. } \\
\text { Start pre-marriage counseling of the } \\
\text { couples. Marriage registrar should be } \\
\text { involved in pre-marriage counseling. }\end{array}$ \\
\hline $\begin{array}{l}\text { Lack of active support by the community } \\
\text { leaders for male methods. }\end{array}$ & $\begin{array}{l}\text { Male community leaders need to be } \\
\text { involved in a larger way. They need to be } \\
\text { made more interested in the FP program } \\
\text { through orientation programs, involving } \\
\text { them in local level planning exercises and } \\
\text { periodic discussion on service delivery } \\
\text { issues. }\end{array}$ \\
\hline $\begin{array}{l}\text { Service delivery centers (GOB and NGO) } \\
\text { are utilized more by females and children. }\end{array}$ & $\begin{array}{l}\text { Time for service delivery should be } \\
\text { determined according to the availability of } \\
\text { the male community members. May be an } \\
\text { evening clinic for male can cater to the } \\
\text { need. Services can be provided on holidays } \\
\text { and weekends. } \\
\text { Workers should be available for } \\
\text { motivational activities beyond working } \\
\text { hours. }\end{array}$ \\
\hline $\begin{array}{l}\text { There is a huge number of Health and FP } \\
\text { staff at different levels who are under- } \\
\text { utilized. }\end{array}$ & $\begin{array}{l}\text { Structural alignment/ integration of vertical } \\
\text { service delivery systems of Health and FP } \\
\text { is one solution. } \\
\text { Establish work accountability at all levels. } \\
\text { Develop workplans for all categories of } \\
\text { staff based on local problems identified by } \\
\text { the service providers themselves. } \\
\text { Bring attitudinal change among staff } \\
\text { through facilitative supervision. } \\
\text { For better support, orient the doctors of } \\
\text { Directorate of Health on FP methods, side } \\
\text { effect and complication management. }\end{array}$ \\
\hline & Strengthen the medical curriculum \\
\hline
\end{tabular}




\begin{tabular}{|c|c|}
\hline ISSUES/EXPERIENCES & RECOMMENDATIONS \\
\hline & $\begin{array}{l}\text { particularly by including vasectomy in } \\
\text { surgery and tubectomy in Ob/Gyn. } \\
\text { People's representatives should be in } \\
\text { control of service delivery at thana level } \\
\text { and below. }\end{array}$ \\
\hline $\begin{array}{l}\text { Male adolescents and unmarried youths are } \\
\text { not given due attention. }\end{array}$ & $\begin{array}{l}\text { Target male youths in the FLE programs } \\
\text { both in the NGO and GOB programs } \\
\text { particularly providing education on } \\
\text { adolescent health and sexuality. }\end{array}$ \\
\hline $\begin{array}{l}\text { There are management problems in } \\
\text { connection with client referral for clinical } \\
\text { methods particularly the discordance } \\
\text { between the medical and non-medical staff } \\
\text { of the FP Directorate. }\end{array}$ & $\begin{array}{l}\text { Local government institutions should be } \\
\text { made stronger to make all categories of } \\
\text { staff to work sincerely serving the people. }\end{array}$ \\
\hline $\begin{array}{l}\text { Poorly performed vasectomy procedures } \\
\text { have damaged the image of the method. }\end{array}$ & $\begin{array}{l}\text { Skill training programs need to be } \\
\text { strengthened particularly the practical } \\
\text { sessions. For this the flow of clients needs } \\
\text { to be increased at the training centers. } \\
\text { NGOs need to be involved in this } \\
\text { connection in a very active way. } \\
\text { A system of regular contraceptive } \\
\text { technology updating needs to be set up in } \\
\text { collaboration between DFP and NIPORT. } \\
\text { Strengthen on-site training through the } \\
\text { medical supervision system with more } \\
\text { collaboration between NIPORT, DFP and } \\
\text { FPCST. }\end{array}$ \\
\hline $\begin{array}{l}\text { Service providers and field workers are not } \\
\text { enthusiastic to work. They are also not } \\
\text { themselves using the different methods. }\end{array}$ & $\begin{array}{l}\text { In connection with the activization of the } \\
\text { service providers and field workers, the } \\
\text { contraceptive use status of the providers/ } \\
\text { workers should be collected. }\end{array}$ \\
\hline $\begin{array}{cl}\text { Missed opportunities of male services at: } \\
\begin{array}{cl} & \text { Medical College Hospitals. } \\
- & \text { District Hospitals. } \\
\text { - } & \text { Specialized hospitals. }\end{array}\end{array}$ & $\begin{array}{l}\text { Set up in-reach client referral system for } \\
\text { FP services in such hospitals. }\end{array}$ \\
\hline $\begin{array}{l}\text { No male services are offered at the } \\
\text { MCWCs. This is a medical barrier. }\end{array}$ & $\begin{array}{l}\text { i. Provision should be made to make male } \\
\text { services available at the MCWCs. }\end{array}$ \\
\hline The different aspects of the male & i. Set up a special male involvement project on a \\
\hline
\end{tabular}




\begin{tabular}{|c|c|}
\hline ISSUES/EXPERIENCES & RECOMMENDATIONS \\
\hline $\begin{array}{l}\text { involvement programs need to be thought } \\
\text { out in a comprehensive manner. }\end{array}$ & $\begin{array}{l}\text { pilot basis focusing on all aspects including IEC, } \\
\text { community mobilization, activation of service } \\
\text { providers and making them more skillful etc.) }\end{array}$ \\
\hline $\begin{array}{l}\text { There has been a decline in the acceptance } \\
\text { of male voluntary sterilization (vasectomy) } \\
\text { as a method due to: }\end{array}$ & $\begin{array}{l}\text { More IEC for wives. } \\
\text { Intensive generalized IEC. }\end{array}$ \\
\hline 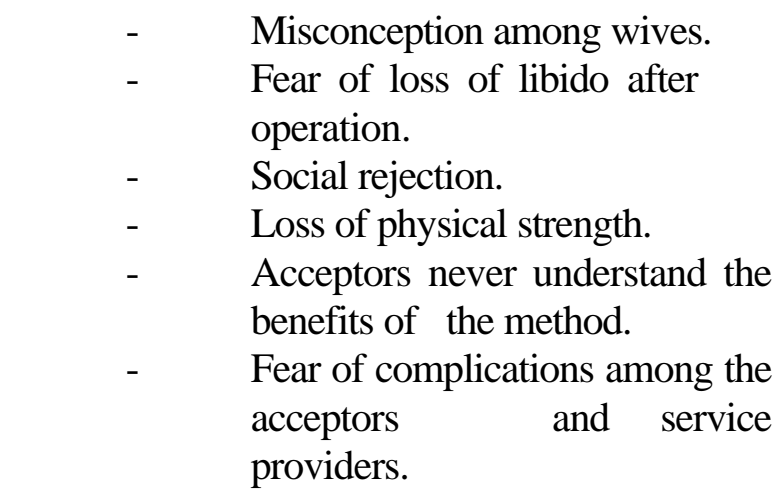 & $\begin{array}{l}\text { Use satisfied vasectomy acceptors. } \\
\text { Start/Initiate couple counseling sessions. }\end{array}$ \\
\hline
\end{tabular}




\section{Group 3}

\section{Training Needs for Service Providers}

The existing training institutions should be strengthened by incorporating training elements on male participation in FP program.

- Types of training available:

- $\quad$ Motivational training at the field level

- $\quad$ Counselling training

- Training of the service providers-

- $\quad$ Clinical and

- $\quad$ Non-clinical

- Management training for supervisory staff

- Training and IEC materials should be developed considering socio-cultural context of the country for attitudinal changes of the trainees to increase male participation.

- Appropriate and standard counselling training module should be developed for all levels of the service providers which should be followed at all levels.

- More physicians, i.e, Medical Officer (MCH-FP) and Medical Officer (FW) should be trained on No-Scalpel Vasectomy (NSV).

- The contents and techniques for intersectoral mobilization should be inbuilt in the training curriculum. 


\section{Group 4}

\section{Potential Areas for Future Research on Male Participation/ Innovative Programmatic Interventions}

Towards ensuring a greater male participation in family planning programme, the role of male can be classified in terms of a) user (practicing a male method); b) supporter (encouraging respective wife or others to practice/ adopt a contraceptive method); c) provider (providing family planning services and motivation). One can play either a single or a multiple role aimed at future augmentation of the contraceptive prevalence rate (CPR). Keeping in view the above key role of male in FP programme, the group recommended some potential areas of analytical research, operations research and innovative programmatic interventions. In this summary recommendations on a few priority areas of research and programmatic interventions are synthesized for immediate action.

\section{Analytical Research Topic/Areas:}

- A situation analysis including KAP survey should be undertaken to ascertain the current state of male participation in family planning programme in Bangladesh.

- A critical review of existing government policies towards augmenting male participation in family planning including evaluation of policies, incentive structure, major actors involved, political commitments, etc. is needed for future directions of male participation.

- A cost-benefit analysis of a greater participation of male vis-a-vis female in family planning programmes both in the short-run and long-run period from the national point of view is required.

- A critical review of the quality of the existing health and family planning facilities in Bangladesh in terms of both physical and logistics and human resources will facilitate rendering of services for a greater male participation in family planning.

- A evaluation of the training needs for health and family planning staff including doctors at different level is needed for achieving a greater participation of male in family planning.

- A review of various problems encountered by both male and female in adopting family planning methods is necessary to be undertaken particularly with reference to: side effects and client satisfaction/confidence

- The determinants of male FP methods acceptors, non-acceptors, dropouts and opponent need to be identified.

\section{Operations Research Topics/Issues}


Operation Research can be undertaken on the following topics/issues on experimental basis in selected areas:

- Problems encountered by males/husbands adopting male methods particularly with reference to:

- Side effects

- Client satisfaction and confidence on male methods as well as on service providers

- Social, cultural and religious taboos

- Misconception on contraceptive methods.

- Characterization of male FP methods acceptors, non-acceptors, rejecters and opponents.

- Use of indigenous IEC strategy, campaigns, materials, and programmes towards male participation.

- Determinants of decision-making process of contraceptive use by the newlywed couples.

- Effectiveness of use of mobile medical teams for sterilization, particularly for male procedures.

- Measures for the relative efficiency of joint or separate motivation of husband and/or wife.

- Implementation of the lessons learnt on effective male participation from the existing family planning programme both at home and abroad.

\section{Programmatic interventions}

Some of these recommended programmatic interventions can be tested/implemented by MOHFW and DFP at the selected field spots through orientation to the local level officials.

- Fixing up a date as male/husband day in the existing static facilities such as satellite clinics, FWCs and THCs for special service delivery.

- Review of job description of health and family planning staff to have effective male contact particularly the role of FPIs, MAs, and HAs.

- Revision of the existing training curricula and modules by incorporating male motivational strategies and techniques for popularizing male FP methods and for male participation in FP programmes.

- Strengthening of the sterilization training programme for the doctors. 
- Reactivization of the local FP committees for effective participation of males in FP programmes through community and religious leaders, NGOs and inter-sectoral efforts.

- Extensive use of mass media for sensitizing male participation and on use of male methods.

- Development of IEC messages and materials on male motivation and on safe and easy use of male methods both for target audience as well as for the field-workers.

- Increased compensation payment to vasectomy acceptors.

- Popularization of multi-purpose use of condom for prevention of unwanted births, STDs and HIV.

- Review of service provider's benefits and prospects. 


\section{Group 5}

\section{Community Participation and IEC to Increase Male Involvement}

The group consisted of ten members representing IEM Unit of the Directorate of Family Planning; Jahanagirnagar University, national and international NGOs and private research organizations involved in development of communications including FP/MCH. Dr. Syed Jahangeer Haider, Executive Director READ performed the role of Group leader and Facilitator. The group identified the critical areas of concern for male participation, reviewed past IEC performance on the referred subject; developed specific recommendations and identified targets: audiences, messages and the media.

\section{Areas of Concern:}

The group defined male participation as:

i. $\quad$ The level of support to generate and enhance male involvement; and ii. The level of use of FP methods/contraceptives.

The group developed a matrix on the variables of support and level of use of contraceptives specifying the findings of 1993-94 DHS as an instrument to focus the areas of concerns of male involvement:

Matrix focusing the concerns on male involvement:

Distribution of the responses of currently married women on the levels of current use of contraceptives; and approval of FP by gender:

\begin{tabular}{|c|c|c||}
\hline \hline Gender & Current use of contraceptives & Level of approval of FP \\
\hline Female & $89 \%$ & $?$ \\
\hline Male & $11 \%$ & $89 \%$ \\
\hline
\end{tabular}

While reviewing the matrix, the group identified the level of "support/approval" of the wives on the use of contraceptives by their respective husbands as a critical area of concern.

\section{- Review of past IEC performance on male motivation}

The group assessed that the past IEC interventions were focussed on program packages targeted to either females or for both males and females, but it failed to launch any IEC intervention exclusively to evoke male participation (support and use) in FP. 


\section{Recommendations for future communication strategies}

The communication strategies were designed separately to: (i) induce support of male involvement; and (ii) accelerate the use of contraceptives/methods (Vasectomies, Condoms, Abstinence) by the males. The IEC interventions were designed to influence changes at the levels of: (i) Knowledge; (ii) Attitude/Beliefs; and (iii) Behaviors.

\section{- Priority IEC Strategies to Induce Support:}

- Target Audiences: (i) Head of the Household/elderly relatives; (ii) Village moral (formal and informal leaders): teachers, imams, doctors, UP chairmen/members; (iii) Audiences at informal gatherings: tea stalls, saloons, grocery shops, clubs and associations; (iv) Organized groups/worksites: mothers' clubs, rural credit societies, trade unions; (v) Occupational groups: journalists, Ansars/VDPs, Rickshaw Pullers, Industrial laborers, Political leaders (formal and informal); and (vi) Formal Committees: National Population Council, District, Thana and Union level Health and FP committees.

- Priority Messages: "Use Condoms"; " Vasectomy is safe and simple"; " Males must share Reproductive Responsibility".

- Media Mix: Radio, T.V., Print media and Interpersonal (Group interactions)

- Priority Interventions:

* Orientation programs in groups:

Influence knowledge, attitude and beliefs

\section{Intervention:}

Disseminate standard messages supported inter alia by radio/T.V. and print media.

\section{Person Responsible:}

FPIs, HAs, MAs
Generate support and create social pressure in favor of male participation to contraception.
THFPO, TFPO, MOs, TEOs

Parent Teachers' Associations, village doctors, Religious leaders, Morals: Formal and informal leaders. 
* Social mobilizations: Influence attitude and behavior

Organize rallies with males and females on special days like national population day/week.
DDFP, TFPO, FPIs, Male and female leaders and HAs,FWAs, FWVs, MAs. adult males and youth, users of methods of FP and their elder relatives.

* Institutional Interventions: affect norms and values

Integrate messages on male involvement to FP in the training-1 education curricula.
MOHFW/DG FP, Islamic Foundation, NGOs, MOE, BRDB, Ministry of Home
Training of Imams, Ansar/VDP training, Cooperative members, Primary School Teachers' Training.

\section{- Priority IEC Strategies to Accelerate Use of FP Methods by Males:}

- Target Audiences:

* Husbands of semi-permanent FP method users;

* $\quad$ Newly married males;

* $\quad$ Husbands of drop-outs and irregular method users';

* $\quad$ Husbands of oral pill users

* Traditional method users.

- Priority Messages:

Appeal/Advocacy from a vasectomy/condom user; Do not leave all reproductive pains for wives only.

- $\quad$ Media -Mix: Interpersonal communication supported by mass and folk media.

- Priority Interventions:

* Interpersonal contact: To Influence KAP

Conduct Motivation

Education

Conduct Advocacy Programs
FPI, HA, MA

TFPO,MOs, HAs
Male target audiences and female users.

Participants in EPI camps, Village bazars, in FWCs/Sat. clinics with males in the 
afternoon.

\section{CONCLUDING SESSION}

The concluding session of the seminar was held on the following day, the June 26, 1996. Mr. Mohammed Ali, Secretary, Ministry of Health and Family Welfare was the chairman of the concluding session. The guests of honour in this session were Mr. Khairuzzaman Chowdhury, Director General, Directorate of Family Planning, Mr. A.K. M. Rafiquz Zaman, Director General, NIPORT, Dr. Heide Richter, Team Leader, NIPORT-GTZ, Mr. David Piet, Director, OPH, USAID, and Mr. J.S. Kang, Population Specialist, World Bank.

At the beginning of the concluding session Ms. Nancy J. Piet-Pelon, the Chief Rapporteur of the seminar summarized on the issues as well as the achievements of the seminar. Ms. Piet-Pelon mentioned that five papers were presented in this seminar which gave an outline of what male involvement was. She also explained that male involvement in family planning was more than just the thinking of man as family planning users and that men were very important part of supportive decision making for using family planning methods by their wives. She further said that involvement of male as policy makers, researchers and service providers represented male involvement in family planning. Besides, continued efforts to empower women was also a sort of male involvement. There was a delicate balance between the empowerment of women and the involvement of men in family planning she added. Hence, she suggested for changing $\mathrm{MCH}$ to MMCH meaning Maternal, Men and Child Health.

With regard to the service provision, Ms. Piet-Pelon said that the women-to-women contact at the field worker level in satellite clinics and FWCs was foremost. IEC had been produced with women in mind. She said that through the family planning programme women had been moving beyond the traditional, social and cultural barriers to make decisions about their reproductive life. She also mentioned that men had reproductive health and male family planning needs which must be met by the same system as now reaches to the women. The programme could not afford to lose what it had worked so hard to achieve. At the same time, the programme needed to recognize that men could do much more than they were doing both as users of family planning methods, as well as supportive partners of their wives' decisions regarding contraception.

Ms. Nancy J. Piet-Pelon further said that proactive support of male at all levels was needed. It was also important at the policy level. It was necessary for example, to look into the possibility of changing the hours of family planning services to make these more convenient for men, altering the role of male providers to encourage their direct participation in male services, particularly information services or offering vasectomy through mobile services facilities rather than static facilities only and the like. In addition to that, training for male involvement would be needed. The development for couple counselling training was suggested, including exclusive counselling for men. Training for service providers in the effective delivery of both clinical and non-clinical male methods also needed improvement. She mentioned that many areas of research for the purpose of clarifying the needs and concerns of men had been suggested including prioritization was mentioned particularly in the areas of service delivery, IEC and training.

Following the presentation of Ms. Piet-Pelon, Mr. David L. Piet, Director OPH, USAID, Mr. J S Kang, Population Specialist, World Bank, Dr. Heide Richter, Team Leader, NIPORT-GTZ, Mr. Khairuzzaman Chowdhury, Director General, Directorate of Family Planning, and Mr. A.K.M. 
Rafiquz Zaman, Director General, NIPORT took part in the discussions. In his speech, Mr. David Piet congratulated the Ministry of Health and Family Welfare, NIPORT, GTZ, AVSC International and the Population Council on taking initiative of such a seminar. He said that male involvement like other interventions was constrained by a number of organizational, personal or managerial aspects. For increasing male involvement in family planning he suggested to strengthen the cooperation and coordination across the Directorate of Family Planning and the Directorate of Health Services. Referring to the conflict between the technocrats and generalists, and the doctors and non-doctors in the programme he said that the issue should be resolved because, male involvement needed total involvement of all including the provides of clinical services.

Mr. J.S. Kang, Population Specialist of the World Bank, said that by common consent Bangladesh family planning programme had an exceptional achievement to its credit. He added that there was a need to consolidate these achievements and maintain if possible further accelerate the rapid fertility decline. One of the important things would be to improve the quality of services in the programme he opined. Last two days review of findings, analysis and thinking would contribute to that objective. He observed that there had been a drastic decrease in the use of male methods over the last ten years. Twenty thousand vasectomies were done in a month in the mid eighties. Compared to less than a thousand in a current month. However the use of condoms had increased by nearly 33 percent since the mid eighties. Overall prevalence for male methods had come down substantially. He commuted that the programme was having female orientation since the male methods accounted for less than 10 percent. This disproportionately heavy burden on the females was remarkable when everything the country as a whole stoods to gain by the success of the family planning programme. This had been happening even when male methods were convenient and much safer. He observed that in the reporting of MIS male methods tended to get heavily over reported and suggested corrections. Education of couples, dispelling of rumours regarding side effects and improving the quality of services were needed to be done immediately, he added.

Dr. Heide Richter, Team Leader, NIPORT-GTZ said that gender was not about women alone but it involved both men and women and should take into account the role of society and the changes therein. This seminar had a gender perspective he observed, and this was relevant in the sense that men more than women were the decision makers in family planning and in fact till this day they wielded more decision making power because in society traditionally they held that role. From Ms. Nancy Piet's presentation it was learnt that this seminar had elaborated on perpetuating the success achieved for the promotion of women's active participation in decision making. Dr. Richter observed that there was no denying the fact that men should be more involved and more reminded of their responsibility and their role in society should be acknowledged but it should not mean that the success achieved so far in favour of women should not be pursued further. She stressed on the need for motivation of men in decision making to promote family planning methods, motivation to support their wives adopt family planning methods themselves, make it possible for their wives to take this active role in decision making and to support their wives in active decision making for their own health so that mutual consultation between husband and wife could be encouraged for coming to a joint decision. Dr. Richter said that GTZ would be to happy join in further follow-up of the recommendations of the seminar.

Mr. Khairuzzaman Chowdhury, Director General, Directorate of Family Planning thanked the organizers and the participants of the seminar. He said that he would like to have only those recommendations which would be implementable and workable. Mr. Cowdhury observed that 
male involvement did not necessarily mean that the number of vasectomies conducted should be increased or the use of condom should register an increase. The involvement of both men and women in taking decisions together in planning the family size or using contraceptives was important. This involvement of male should come first and then the decision on the method could follow. Men should be brought in a large number as acceptors of family planning methods. The working time set for FWVs and the satellite clinics should be changed. The involvement of the male functionaries also needed to be ensured. Reorientation of FPIs and also the MAs should start immediately. He assured that the recommendations would definitely be utilized for more involvement of male in the family planning program.

Mr. A K M Rafiquz Zaman, Director General, NIPORT, in his speech said that he wanted the seminar to be result oriented. He suggested that there could be a working group with two representatives from each group with NIPORT as the facilitator. This working group would finalize and prioritize recommendations by discussion before presenting them to the MOHFW, the Policy Makers, the Program Implementers and NGOs.

In his concluding remarks, Mr. Mohammad Ali, Secretary, Ministry of Health and Family Welfare, said that we should initiate concrete, durable, implementable and need-based programmes to overcome our deficiencies. He said that male participation was in fact a problem of motivation. The male members of the family needed to be motivated cutting across the ego, male fear as well as by inculcating a greater sense of responsibility on the male members. He said that the family planning workers should understand this problem and if necessary the programme should be revised to ensure increased male participation. Mr. Ali assured that male field workers could be deployed for home visits if found appropriate. He suggested for another evaluation session after six months to find out what results had been achieved from the deliberations of this seminar. Based on the recommendations of this seminar as well as these of the follow up seminar concrete steps could be taken to ensure more active involvement of male in the family planning activities. 


\section{SEMINAR EVALUATION}

\section{A. Objective and Methodology}

An evaluation was carried out at the end of the seminar. The objective of the evaluation was to determine the expectation and the level of satisfaction of the participants for attending the seminar as well as to seek suggestions for the future development.

Altogether 120 participants from 15 government offices, 10 NGOs and 5 donor agencies attended the seminar. An evaluation checklist was administered to all the participants, of whom 50 participants returned it with their comments.

\section{B. Findings}

\section{Expectation of the participants:}

- Male motivation campaign (e.g. IEC) for effective male participation would be added in the national FP programme (initially start as an operational research programme)

- Effective measures should be initiated to ensure balanced gender involvement through FP-MCH counselling jointly with the spouses and to undertake measures for motivations and involvement more males both as providers and acceptors of family planning methods.

- Modifications of Training Curriculum

- Undertake research on male participation in the MCH-FP programme and disseminate findings at the field level

- Arrange an orientation seminar for all trainers on male participation in family planning 


\section{Satisfaction of the participants:}

Table 1

Percent Distribution of the Participants According to Seminar Facilities

\begin{tabular}{||l|l|l|l|l||}
\hline \hline Categories & $\begin{array}{l}\text { Seminar } \\
\text { Facilities }\end{array}$ & $\begin{array}{l}\text { Logistics } \\
\text { Arrangements }\end{array}$ & $\begin{array}{l}\text { Seminar } \\
\text { Presentation }\end{array}$ & $\begin{array}{l}\text { Group } \\
\text { Discussion }\end{array}$ \\
\hline Excellent & 27.9 & 27.9 & 20.9 & 51.2 \\
\hline Good & 48.8 & 58.1 & 37.2 & 25.6 \\
\hline Satisfactory & 23.3 & 11.6 & 41.9 & 0.0 \\
\hline Not satisfactory & 0.0 & 2.3 & 0.0 & 0.0 \\
\hline Total N & 43 & 43 & 43 & 43 \\
\hline
\end{tabular}

\section{Suggestions of the participants for improvement of the seminar}

The participants gave a lot of suggestions for the improvement of this type of seminar. Some of these suggestions involved policy issues and majority of them covered the management aspects.

\section{Policy Issues}

- This type of seminar should be expanded to the field levels so that it could be largely participated by the community leaders.

- The seminar recommendations should be implemented as soon as possible.

- The seminar should be held outside Dhaka with small groups and more intensive participation

- It would be better if more mid-level managers attended the seminar

- The duration of seminar should be increased up to at least three days. There should be a full day for theoretical discussion

\section{Management Aspects}

- The schedule of the seminar should be strictly followed. There should be more effective time management. The first part of the seminar, i.e., paper presentation was too lengthy.

- The papers presented should be reviewed by a small group of experts to ensure their quality. The papers should be supplied to the participants beforehand. 
- The leader of the group should be selected with due consideration. The leader should be knowledgeable and committed to the cause. It was noticed that whole exercise of the group work was ruined for weak presentation and answering.

- The group should be harmonious so that level of discussion could take place in a balanced way. This however would also hamper the inclusion of diverse issues. Moreover, the groups should be kept as small as possible (not exceeding 10 persons). 


\section{PROGRAMME SCHEDULE}

\section{$\underline{\text { June 25, } 1996}$}

08:30- 09:00 Registration

09:00- 09:05 Recitation from the Holy Quran

09:05- 09:15 Welcome Address

09:15- 09:30 Introduction and Objectives of the Seminar

09:30- 10:45 Presentation of Papers

09:30- 09:45 Male Involvement in Family Planning Program: Bangladesh

09:45- 10:00 Role of Male as the User of Contraceptive Methods

10:00- 10:15 Males as FP-MCH-RH Service Providers

10:15- 10:30 Male Motivation for Promotion of Women's Participation in Decision-Making- An Important Element of Family Planning Program

10:30-10-45 Highlights of Regional Male Involvement in FP Programs

10:45- 11:15 Tea Break

11:15- 13:00 Small Group Discussion

13:00- 14:00 Lunch and Prayer Break

14:00- 16:30 Small Group Discussion

\section{June 26, 1996}

09:00- 10:00 Finalization of Group Recommendations

10:00- 10:30 Tea Break

10:30- 13:00 Group Presentation and Recommendations

13:00- 14:00 Lunch and Prayer break

14:00- 15:00 Concluding Session 
VIII. LIST OF PARTICIPANT

\section{NAME OF ORGANIZATIONS}

Ministry of Health and Family Welfare

Directorate of Family Planning

Directorate of Health Services

PDEU, Ministry of Planning

National Institute of Population Research and Training (NIPORT)

\section{NAME OF PARTICIPANT}

Mr. Md. Shirajul Islam

Joint Secretary

Mr. Md. Abdullah

Assistant Chief

Mr. Abul Kalam

Deputy Chief

Mr. Khairuzzaman Chowdhury

Director General

Dr. Jahiruddin Ahmed

Director, $\mathrm{MCH}$

Mr. Tofayel Ahmed

Project Director, SMIS

Prof. A. K. Shamsuddin Siddiquey

Director General

Dr. Nurul Anowar

Deputy Director Primary Health

Mr. Joinul Abedin

Deputy Director

Mr. A. K. M. Rafiquz Zaman

Director General

Dr. Ahmed Al-Sabir

Director (Research)

A. N. M. A. Selim Khan

Director (Training)

Mrs. Farida Mabud

Senior Research Associate

Mr. S. A. Mannan

Deputy Director (Admin.)

Mr. Shahin Sultana

Research Associate

Dr. Mizanur Rahman 
NAME OF ORGANIZATIONS

Training (NIPORT)

Bangladesh Bureau of Statistics

Bangladesh Rural Advancement Committee (BRAC)

International Centre for Diarrhoeal Disease Research Bangladesh (ICDDR,B)
NAME OF PARTICIPANT

Instructor (Medical)

Md. Ahsanul Alam

Statistician

Mr. Subrata Kumar Bhadra

Statistician

Mr. Mahfuzur Rahman

Instructor

Mr. Zahidur Rahman

Librarian

Mr. Shahadat Hossain

Joint Director

Dr. A. Mushtaque R. Chowdhury

Director Research

Dr. Shaheduzzaman

Assistant Director

Dr. Barket-E-Khuda

Project Director

MCH-Extension Project (Rural)

Mr. Mehrab Ali Khan

Demographer

Dr. A. Razzaque

Research Fellow

Dr. Radheshyam Bairagi

Director Population Studies Center

Dr. Heide Richter

Team Leader

Ms. Jutta G. Teigeler

Training Advisor

Mr. Habibur Rahman

Associate Advisor

Dr. Nilufar K. Jaha

Senior Programme Officer

Mr. Nazrula Isalm

Senior Programme Officer 
NAME OF ORGANIZATIONS

The Population Council

AVSC International

USAID

UNFPA

Pathfinder International

Grameen Bank

\section{NAME OF PARTICIPANT}

Dr. Ubaidur Rob

Programme Associate

Ms. Nancy J. Piet-Pelon

Consultant

Dr. Naushad Faiz

Post-Doctoral Fellow

Dr. Syed Nahid Mukit Chowdhury

Senior National Fellow

Ms. Nahid Kamal

National Fellow

Mr. Sayyied B. Kabir

National Fellow

Ms. Ismat Bhuiya

Research Officer

Dr. Sharif Md. Ismail Hossain

Research Officer

Mrs. Unnati Rani Shaha

Computer/Research Assistant

Ms. Shirin M. Khuda

Research Assistant

Dr. A. J. Faisel

Country Director

Mr. Ahmed Al-Kabir

Regional Programme Coordinator

Mr. David Piet

Director, OPH

Ms. Tahera Ahmed

Senior programme Officer

Mr. Saiful Islam

Program Manager

Dr. Ferdousi Begum

Assistant Medical Program Officer

Dr. Khairul Islam

Program Manager 
NAME OF ORGANIZATIONS

Family Planning Services and Training Centre (FPSTC)

Family Planning Clinical Services Training (FPCST)

Canadian International Development Agency

(CIDA)

Swanirvar Bangladesh

Bangladesh Population and Health Consortium

(BPHC)

The Asia Foundation (TAF)

World Health Organization (WHO)

World Bank

Associates in Training and Management (AITAM)

Statistics Department

Jahangirnagar University

Centre for Population and Development (CPD)

Bangladesh Association for Voluntary

Sterilization (BAVS)

Palli Shishu Foundation, Bangladesh (PSF,B)

Concern Women for Family Planning (CWFP)
NAME OF PARTICIPANT

Mr. Abdur Rouf

Executive Director

Dr. C. P. Muskey

Team Leader

Dr. Nancy Gerein

Director Population
Mr. Syed Mamunur Rashid Project Director

Ms Anne Garbutt

Project Coordinator

Ms. Kirsten Lundeen

Programme Manager

Dr. Shambhu P. Acharya

Programme Manager

Mr. J. S. Kang

Population Specialist

Mr. Faruque Ahmed

Population Specialist

Dr. S. M. Shahidullah

Executive Director

Dr. Kazi Saleh Ahmed

Professor Dept. of Statistics

Dr. Md. Kabir

Professor Dept. of Statistics

Mr. Nazmul Haque

Executive Director

Dr. Mizanur Rahman

Executive Director

Mr. G S. Rahman

Executive Director

Mrs. Mufaweza Khan

Executive Director 
NAME OF ORGANIZATIONS

Programme for the Introduction and Adaptation of Contraceptive Technology (PIACT)

Research Evaluation Associates for Development (READ)

John Hopkins University Center for Communication Programs (JHU/CCP)

Associates for Community and Population Research (ACPR)

SAPTA

\section{NAME OF PARTICIPANT}

Mr. Abu Yusuf Chowdhury

Executive Director

Dr. Syeed Jahangeer Haider

Executive Director

Ms. Yasmin Khan

Programme Officer

Mr. Jamil Hosssain Chowdhury

Director Training and Evaluation

Mr. S. Majid

Executive Director 


\title{
Male Involvement in Family Planning Program: Bangladesh
}

\author{
Ubaidur Rob* \\ Shirin M. Khuda \\ Abu Yusuf Choudhury ${ }^{* *}$
}

Paper Presented at the Workshop on Male Involvement in Family Planning: A Challenge for the National Program. Jointly organized by NIPORT, GTZ, AVSC and the Population Council. Dhaka, June 25-26, 1996.

* The Population Council, Dhaka, Bangladesh.

** PIACT, Bangladesh.

\section{Introduction}


Equity in gender relations and responsible sexual behavior underscores the need for men's active involvement in family planning. Male involvement in family planning is emphasized as supportive male partner facilitates women's contraceptive use. Besides, service delivery approaches mainly offering female contraceptive methods such as oral pills, injectable, IUD, and tubectomy without involving men will be partially effective at best, particularly in the societies where males hold higher social status and decision-making power. Furthermore, the advent of acquired immunodeficiency syndrome (AIDS) pandemic and rapid expansion of sexually transmitted diseases (STDs) have also provided strong grounds for men's active involvement through condom use (Green, Cohen, and ElGhouayel, 1995). The availability of no-scalpel method of vasectomy has also renewed interest in male sterilization among service providers and prospective users (FHI, 1992).

Male involvement refers to the ways in which men relate to reproductive health problems, reproductive rights and reproductive behavior (Green, Cohen, and El-Ghouayel, 1995). Male involvement in family planning has two major aspects: (i) the way men accept and support their partners needs, choices and rights in fertility regulation, and (ii) men's own contraceptive use and sexual behavior. Commonly, male involvement in family planning signifies two distinct yet interrelated programmatic goals of encouraging the use of male contraceptive methods and expanding men's involvement in family planning decision making process (Donahue, 1995). The terms male responsibility and participation are often used to portray male involvement. Responsibility stresses the need for men to shoulder the consequences of their sexual and reproductive behavior, such as caring for offspring, using contraceptive methods, and practicing safe sexual behaviors to protect themselves, their partners and their families from STDs, including HIVs. Participation refers to men's supportive role in their families, communities and work place to promote gender equity. It suggests a more active role for men in both decision-making and behaviors, such as sharing fertility related decision with partners, supporting partner's reproductive choices and using family planning methods. In general, men possesses a higher potential of contribution to family planning service delivery as well as in the extension of relationships between partners and improved communication regarding reproductive goals within the prevalent patriarchal system (Green, Cohen, and El-Ghouayel, 1995).

\section{Country Profile}

The People's Republic of Bangladesh, the ninth most populous country in the world, is also one of the poorest. Bangladesh with a total land area of 147,570 square kilometers, situated in the eastern part of the Indian sub-continent is low-lying riverain country with tropical monsoon climate. The economy of Bangladesh is primarily agrarian. The country has an estimated population of 122 million in 1996. It has also a very high population density with 2250 person per square mile. Bangladesh has experienced a significant fertility decline due to an effective family planning program over the past decade. The total fertility rate has declined from 6.5 in 1975 to less than 4 in 1994 (Mitra et al., 1994). The contraceptive prevalence rate, at 45 percent for all methods and 36 percent for modern methods, is the highest among the south Asian countries.

Ever since independence, the Government of Bangladesh has been explicitly concerned with the high rate of population growth and devoted a great deal of efforts to implement a comprehensive health and family planning program. The government views rapid population growth as the leading problem, and the national population program is an integral component of the country's overall development activities. Bangladesh has adopted an explicit population policy with the objective of 
reducing fertility and growth rates and set demographic targets in order to achieve specific population policy objectives in each five year development plan (Rob and Cernada, 1993).

The head of the government provides overall leadership to the program. The government's broad demographic goal is to achieve replacement level fertility by year 2005 . Strategies to reduce fertility include the integration of health and family planning services at the grass roots level, the availability of a wide range of contraceptive methods and adequate follow up services. In the public sector, the program is implemented by the Ministry of Health and Family Welfare in coordination with nine other development ministries. Presently, the government program extends throughout rural Bangladesh, and include a community based component provided by a work force of 23,000 female field workers, as well as clinical services provided at the union-level $(4,000)$ Family Welfare Centers (FWCs) and 472 Thana Health Complexes (THCs). Since its inception the family planning program has received considerable external assistance. The principal donor agencies include United States Agency for International Development (USAID), World Bank and United Nations Population Fund (UNFPA).

The objective of this article is to examine the status of male involvement within the family planning program in Bangladesh. In addition, constraints in the way of promotion of male method will be discussed in the paper. The family planning activities particularly male involvement in the program have evolved over the years through various phases. The phases highlighting the specified issues will be addressed in the following sections.

\section{Phase I: Introduction and Expansion of FP Efforts}

Concern over high maternal and infant mortality rates along with poor nutritional status of pregnant women played the major role in the inception of family planning program in the then Pakistan. Family planning activities were first initiated by voluntary organizations in the early 1950s and were initially confined in the urban areas. The newly formed Family Planning Association of Pakistan offered only clinical services till 1960. The knowledge of family planning services and use of clinical methods remained considerably low due to non-availability of services in the rural areas. In 1960, the program was modified to include government health clinics as primary service delivery points in order to increase the access of family planning services.

In 1965, the government established an independent family planning program under the guidance of an autonomous organization. The field strategies were revised and demand creation efforts were introduced (Cleland, et al. 1994). The program promoted IUD and male sterilization methods. An outreach system comprised of traditional birth attendants (TBAs), male organizers, female paramedics and program managers was designed to promote family planning services in the rural areas. Program managers at the district level were primarily responsible for implementation and management of family planning activities. TBAs were assigned responsibilities to recruit IUD acceptors and male organizers to motivate prospective vasectomy acceptors. In addition, nonclinical methods such as condom, foam tablet, jelly, and diaphragm were available from all clinics.

Male sterilization program was introduced in 1965. At the beginning, the male sterilization was popular and over one million vasectomies were performed during 1965-70. In contrast, the acceptance of female sterilization remained low (Haider and Kabir, 1989). At the initial stage, males were very conservative and thereby did not want their spouses to approach outsiders for family planning services. Therefore, they themselves took the responsibility of birth control which was 
reflected in high acceptance of male sterilization during this period. Later on, several monetary incentives scheme were introduced in order to promote clinical contraceptive methods. For example, acceptors of sterilization were given a fixed amount of money to cover expenses related to the operation and travel. Field workers and community members were given referral fee on per case basis.

Self-employed agents played a major role in recruiting sterilization acceptors (Cleland and Mauldin, 1991). Large number of vasectomy performance in the late sixties can be explained by the availability of qualified male workers and easier technique compared to tubectomy. Several program managers suggested that the high level of political and administrative commitments accompanied by large financial resources had created instant impact on the acceptance of vasectomy at the early stage of the program. Imposition of sterilization targets and financial assistance were initially effective but subsequently became less effective due to improper use of the system (Cleland et al., 1994).

The newly gathered momentum of family planning activities was halted due to the non-cooperation movement in 1969, and subsequently the war of independence stopped the efforts completely. After independence in 1971, the government was mainly engaged in reconstruction work and family planning activities were virtually absent in the rural areas. The number of vasectomy acceptors declined to less than 1000 cases per year during 1970-74. The impact of program efforts on contraceptive use was modest and the contraceptive use rate increased from 3.9 percent in 1969 to 7.7 percent in 1975 (Haider, Streatfield and Karim, 1995).

\section{Phase II: Integration of Health and Family Planning Services}

In 1975, a separate directorate was established to spearhead population planning activities in Bangladesh. Several organizational steps were taken to co-ordinate family planning activities in conjunction with health services. To reduce high maternal and infant deaths the program changed its target audience, and shifted its focus towards females by promoting female methods. As part of promotional activities several steps including motivation, availability of services, increase accessibility and distribution of female contraceptives were undertaken. To achieve greater female involvement the program was reorganized at the field level. The reorganization withdrew male workers and deployed females in large numbers as front line field workers. A rigorous media campaign was started and special steps were taken to motivate females to accept longer acting methods. Moreover, introduction of minilap technique and availability of trained female paramedics encouraged females to accept clinical methods, particularly IUD and tubectomy (Haider and Kabir, 1989). This resulted in reduction of male methods acceptance.

The reorganized program also deployed a cadre of full-time qualified male supervisors. In addition, subdivisional officers were recruited to intensify program supervision at the thana level. Service infrastructure was constructed at the thana level to provide services in the areas where facilities were not previously available. The government established hundreds of Family Welfare Centers (FWCs) in the rural areas and THCs extended services through holding special camps at FWCs. Performance monitoring was introduced for ensuring effective program management. Population education curricula were incorporated at the school level. Furthermore, maternal and child health $(\mathrm{MCH})$ education was introduced in women's development projects.

Compensation Payment for Vasectomy Acceptors: Absence of major side-effects and higher use 
effectiveness are the two major reasons for the popularity of vasectomy in both developed and developing countries. Voluntary sterilization is widely practiced in Bangladesh. In 1993, approximately 21 percent of the contraceptive users were practicing sterilization. Although voluntary sterilization has been included in the national program long before independence, significant increase in the number of acceptors was not observed until the early eighties.

Considering the fact that many couple in Bangladesh want sterilization but does not possess sufficient financial resources to undergo the operation led the government to introduce a system of compensation payment for sterilization acceptors (Table 1). The payment was designed to cover financial costs related to wage loss, transportation and other incidental expenses. To ensure better medical attention, a nominal amount of monetary incentives for the service providers was incorporated in the compensation payment system. Referral fee was paid to field workers, TBAs, and self-employed agents. Later on, the compensation system was expanded to provide sterilization acceptors with the surgical apparel (saree and lungi) for maintenance of post operative cleanliness.

The compensation payment was raised in March 1983 for vasectomy acceptors but due to inflation, this increase was even less than the amount paid in 1977 (Huq and Ahmed, 1989). Referral fee for all types of referrers was equalized in March 1983 and this eliminated the financial advantage of the TBAs for referral. A worker-based monthly target of two sterilizations and one IUD acceptor was introduced in 1983. The government in 1984 attempted to restrict canvassing for sterilization by introducing registration system for the informal referrers but the system was not enforced properly. The rigorous application of the method specific 
Table 1

\section{Compensation Payment for Vasectomy Services}

\begin{tabular}{||l|c|c|c|c||}
\hline Category & $\mathbf{1 9 6 5 - 7 0}$ & $\mathbf{1 9 7 6 - 8 3}$ & $\mathbf{1 9 8 3 - 8 8}$ & $\mathbf{1 9 8 8 - 9 5}$ \\
\hline$\underline{\text { Acceptor }}$ & 25.00 & 96.00 & 175.00 & 175.00 \\
Referrer & & & & \\
Family planning worker & - & 15.00 & 45.00 & - \\
TBAs & 2.50 & 45.00 & 45.00 & - \\
Other/Self-employed & 2.00 & 35.00 & 45.00 & - \\
Service provider & & & & \\
Doctor & & & & \\
Clinical Assistant & 25.00 & 18.00 & 20.00 & 20.00 \\
\hline \hline
\end{tabular}

targets had a far greater potential influence on efforts and priorities than the referral payment. In order to fulfill fixed targets the workers resorted to coercion, particularly misinformed the prospective acceptors regarding method specific side-effects. Misreporting became rampant, even some punitive measures in the form of delayed salaries and termination from job failed to improve the situation. Subsequently the target system was abandoned by the government in July 1987 (Huq and Ahmed, 1989). The government eliminated financial payment to the agents and field workers in 1988 in response to severe criticism from both local and international media. But compensation payment to the client remained unchanged.

Recently, the government has reintroduced financial payment to the family planning workers in order to cover their transportation costs (Tk. 40.00) for accompanying the prospective sterilization acceptors. Furthermore, the government realizing the fact that due to inflation the real monetary value have declined considerably has just raised the compensation payment from Tk. 175.00 to Tk. 275.00 in January, 1996 but the effect of this changes is yet to early to comment on.

Special Projects on Family Planning: During 1975-80, two special projects named Zero Population Growth Project (ZPG) and Social Marketing Project (SMP) were initiated. The former experimented with developmental interventions as a measure to accelerate support of the communities to accept family planning methods. The latter project was launched in order to intensify family planning facilities through the commercial sector. The ZPG project failed to produce desired results while SMP continued its operation. At present, SMP distributes oral pills, condoms, and oral rehydration salts through a network of some 140,000 retail outlets. Over the years, SMP has played a crucial role in promoting condom in comparison to other sources.

The proportion of condom use in the country supplied by Social Marketing Company (SMC) has fluctuated overtime. It increased from 64 percent in 1983 to 73 percent in 1986, then declined to 41 percent in 1991 before reached to 61 percent in 1993-94 (Mitra et al., 1994). At the national level, field-workers are the primary source of condom while 23 percent of the condom users procured supplies from the private sector. Approximately 67 percent of the users purchased condom either from field workers or from the commercial sector. Moreover, it is amazing that approximately 26 
percent of the husbands procure condoms while rest of the times their wives did the procurement from the field-workers (Haider, 1995).

Non-Government Organization (NGO) Programs: Recognizing the importance and contribution of NGOs in development, the government of Bangladesh gradually included NGOs at the all levels of national planning. An important feature of the government's policy has been to encourage the participation of NGOs in family planning service delivery. The government established a coordinating body to provide both financial and technical assistance to NGOs who are interested to undertake family planning activities in the rural areas. In addition, a separate registration system expedited expansion of NGO programs. Initially, NGO activities were limited to urban areas, but gradually it has been expanded to inaccessible rural areas where government family planning field workers were not posted. Starting from 1985, NGOs were assigned to specific geographic areas which minimized the duplication of services between NGO and GOB workers.

A large part of the Bangladesh's success in increasing contraceptive prevalence rate is attributable to the NGOs. Innovative approaches in service delivery, the introduction of new contraceptive methods, and a policy of providing acceptors with a range choice of methods are cited as key components of NGO programs. In recent years, NGOs distributed approximately one-third of oral pills, condoms and injectable, and provided services to one-fourth of all eligible couples. In addition, NGOs participated in activities related to immunization, nutrition, training of TBAs, urban health and community mobilization for income generation. Major NGOs in family planning activities include the Family Planning Association of Bangladesh (FPAB), the Concerned Women for Family Planning (CWFP), the Bangladesh Rural Advancement Committee (BRAC), the Social Marketing Company (SMC), and the International Center for Diarrhoeal Disease Research, Bangladesh (ICDDR,B).

Bangladesh Association for Voluntary Sterilization (BAVS) Program: BAVS, a non government organization was established in 1974 to provide quality sterilization services. The first clinic was opened in 1975 and by the end of 1989, 25 clinics were providing family planning services all over the country. BAVS clinics were primarily located in the urban areas and were staffed by qualified physicians. Until May 1987, BAVS recruited sterilization acceptors through field agents, most of whom were illiterate. The agents were classified as "registered" and "unregistered" who were paid a fixed amount of money for each case they referred. In addition, the registered field agents were paid a monthly salary if they referred a fixed number of acceptors each month. Unregistered field agents were able to become registered if the assigned number of acceptors were referred for a period of three months.

The number of sterilization acceptors in BAVS clinics gradually increased till 1986. At the beginning, higher number of female sterilizations were performed in BAVS clinics. The male-female sterilization ratio peaks in the year 1980, when 11 female sterilizations were performed against one male sterilization. However, by the end of 1984 the number of male sterilizations performed at BAVS clinics exceeded the number of female sterilizations. Although BAVS clinics were located in the urban localities, over 80 percent of the acceptors came from the rural areas. The proportion of rural acceptors remained constant over the years.

From 1981, number of vasectomy acceptors increased each year and it reached up to the highest of 60,760 in 1984 and then started to decline. To reverse the falling trend, BAVS redesigned the program activities and hired full-time workers to provide services at the household level (PIACT, 1989). But all this efforts could not revive the falling trend and ultimately the donor agency 
terminated financial assistance in early 1992 (Ahmed et al., 1992). Since inception till December 1989 BAVS performed more than 220,000 vasectomy constituting approximately 15 percent of the total vasectomy performed in the country (Figure 2). Furthermore, if we assume that on the average a sterilization generate 10 couple years of protection (CYP) and 3.5 CYP is required to prevent one birth, BAVS vasectomy program prevented approximately 0.7 million births.

Training of Religious Leaders for Promoting Family Planning: In Bangladesh religious leaders provide formal interpretation of daily life which includes fertility behavior. The interpretation given by them have significant influence upon the rural people. Initially, the rural illiterate were apprehensive about family planning and religious leaders also discouraged them by referring verses from the holy Quran. Since early eighties, several NGOs arranged training program for religious leaders to involve them in family planning activities. As part of this program Islamic Foundation and the Directorate of Family Planning regularly organized training sessions for the religious leaders. In addition, FPAB, Islamic Poribar Kalyan Sangstha, and the Jatiya Tarun Sangha trained more than 10,000 religious leaders on issues related to family planning. A three-day national workshop with religious leaders from all over the country was held in 1985 to discuss issues related to family planning. The training program was able to enlist the support of religious leaders to $\mathrm{MCH}-\mathrm{FP}$ activities through favorable discussions at the Friday prayer and other religious gatherings (Choudhury and Siddiqi, 1992).

\section{Phase III: Recent Years}

The government started several innovative approaches to sustain the success of family planning program. The major objectives of these approaches were: (i) to intensify family planning service delivery in the rural areas, (ii) improve management capacity, (iii) increase community participation,

(iv) increase involvement of NGOs and private sector in service delivery. As part of this program, the World Bank funded Fourth Health and Population Project in 1991. The primary objective of this project was to strengthen services both in the health and family planning sectors. The project is considered to be one of the largest health and family planning program undertaken in Bangladesh. However, no major focus was given on greater male involvement in the Fourth Health and Population project.

To improve the technical expertise of the staff, NIPORT developed a comprehensive training program for both field workers and program managers. For example, program implementation manuals for the field workers, and service delivery manuals specially on sterilization have been prepared. New contraceptives like Norplant, injectable, and the low-dose pill have been introduced. EPI and MCH-FP services were combined at the satellite clinic and more than 30,000 such clinics are organized each month. But all these efforts are primarily directed towards promoting female methods. After 25 years of independence, with high population growth and commendable contraceptive prevalence rate it is high time for the males of the country to come forward and take part in family planning activities and share their responsibilities in equal footing.

\section{Discussion}

There is considerable unmet need for family planning services in the country. An indication of the unmet need, including sterilization is reflected in the large scale performance of menstrual regulation (MR). Since early 1980's, the number of MR acceptors has been increasing steadily. 
Although majority of women requesting MR need temporary methods, undoubtedly a significant portion among them are higher parity couples who are potential candidates for sterilization. Considerable interest for sterilization exists among the relatively lower socio-economic group. This is attributable to the existence of poverty-driven demand. The possibility of major improvements in the socio-economic condition in the near future is very unlikely. This leaves us with the deduction that poverty related demand for contraception in general and for sterilization in particular will continue to exist in Bangladesh (Ahmed, et al., 1992).

Many of the couples who desires no more children and are relatively younger use temporary contraceptive methods. These couples should be encouraged to accept sterilization or practice long term methods. Sterilization particularly vasectomy is one of the best method for these couples who do not want any more children. Between male and female sterilization methods, vasectomy is easier, safer, and requires less recovery time. The couples who want to space births and have less than two children, condom is one of the most suitable method for them. It is easy to use, safe and completely free from side effects. In fact, for the newly married couples condom is the best method. In addition, condom should be used by those husbands whose wives have been prescribed not to use hormonal contraceptives or whose wife's age is above 35 years. In short, condom is a reliable method for all couples. All this points towards greater male involvement both as method users and supportive partners.

Over the years, there has been a shift in the contraceptive method mix in Bangladesh. The acceptance of sterilization particularly vasectomy has declined while those of injectable and oral pills have increased many times. At present, oral pill is the most popular contraceptive method. Up until now large number of males accepted vasectomies in Bangladesh. During the early years of the family planning program, vasectomy acceptors accounted for the two third of all sterilization performance in the country. The availability of trained service providers, establishment of service centers, and large scale recruitment of female field-workers shifted the focus from male to females sterilization.

During the period 1975-81, the modest compensation for sterilization did not appear to have much effect on the number of vasectomies. The number of vasectomies acceptors was about 50,000 per year between 1975-81. A sharp rise in vasectomy acceptance was observed in 1984 due to enhanced referral fees to field workers, setting of sterilization targets, and rise in acceptors compensation. In addition, availability of sterilization services through mobile teams also encouraged a large number of males to accept vasectomy. Financial payment to referrers played an important role in increasing the number of vasectomy acceptors. But due to severe criticism, referral fee were withdrawn in 1988 but acceptor compensation payment remained as part of the program. The target system was more effective intervention than the compensation payments but due to misappropriation and coercion, the system was eliminated in 1987.

Starting from 1987, vasectomy performance declined at an accelerating rate reaching less than 11,000 in 1995, the lowest since 1975 (Figure 1). On the other hand, acceptance of oral pills and injectable have been steadily rising over the years, probably due to improvements in home based delivery of contraceptives (Ahmed, et al., 1992). Both demand and supply factors have contributed to the reduction of the number of vasectomy acceptance. On balance, however, supply factors are more responsible than the demand factors. For example, a large number of service facilities do not possess adequate trained staff to provide quality services. Doctors on deputation from health directorate are more interested in delivery of health services than family planning services. Field workers are less likely to refer sterilization acceptors due to non availability of transportation costs. 
In addition, female family planning field-workers usually communicate with women, and there is no program to reach men either in their work place or at home. Therefore, very few men receive family planning information from the service providers.

Moreover, there is limited number of male contraceptive methods, namely withdrawal, vasectomy and condom. Among these methods withdrawal and periodic abstinence have continued to be play an important role in the program. Approximately 19 percent of the users have been practicing traditional methods in 1993-94 (Mitra, et al., 1994). In Bangladesh, approximately 10 percent of all contraceptive users practice condom and male sterilization. Only through increment of these three methods male involvement can be enhanced. Thus to promote greater male involvement special IEC programs should be designed to motivate male both in terms of supportive partner and contraceptive user.

Bangladesh family planning program with such little involvement of men over the years specifically calls for involving the other half of the population to participate in the program. With female half of the population bearing practically the total responsibility of birth control, it is high time for the male half to come forward to share the responsibility and fulfill their equal obligation. It is practically impossible for the program in the near future to depend solely on the female section to bring the program to its complete success. Thus to uphold the success so far achieved and to attain the desired demographic goal, the program demands that males be more involved in family planning activities. 


\section{References}

Ahmed, J. et al. 1992. "Assessment of Clinical Contraception Services in the Bangladesh Family Planning Program". AVSC, International.

Cleland, J. and W. P. Mauldin. 1991. "The Promotion of Family Planning by Financial Payments: The case of Bangladesh". Studies in Family Planning, 22(1): 1-18.

Cleland, J. et al. 1994. "The Determinants of Reproductive Change in Bangladesh: Success in a Challenging Environment". The World Bank, Washington D.C.

Choudhury, A. Y. and M. S. Siddiqi. 1992. "Evaluation of Religious Leaders' Training Program on FP-MCH". PIACT, Bangladesh and NIPORT, Bangladesh.

Donahue, D. 1995. "Men and Family Planning in Bangladesh: A Review of the Literature". The Population Council. Unpublished.

Faisel, et al. 1995. "Vasectomy Decision-Making in Bangladesh". AVSC, International.

Family Health International. 1992. "Getting More Men Involved". Network 13(1): 4-6.

Green, C. P., S. I. Cohen and H. B. El-Ghouayel. 1995. "Male Involvement in Reproductive Health, Including Family Planning and Sexual Health". Technical Report 28. UNFPA.

Haider, S. J., K. Streatfield and M. A. Karim. 1995. "Comprehensive Guidebook to the Bangladesh Family Planning-MCH Program". Research Evaluation Associates for Development, The Population Council, Ministry of Health and Family Welfare, Government of Bangladesh.

Haider, S. J. and M. Kabir. 1989. "Male Attitude Towards Vasectomy: A Review of Psycho-Social Aspects". AVSC,Bangladesh.

Haider, S. J. 1995. "Interstices Between Distribution and Use of Condoms in the Bangladesh Family Planning Programs". Ministry of Health and Family Welfare, Canadian International Development Agency, Research Evaluation Associates for Development.

Huq, M. N. and S. Ahmed. 1989. "Study of Compensation Payments and Family Planning in Bangladesh: A Synthesis". NIPORT, Bangladesh.

Mitra, S. N. et al. 1994. "Bangladesh Demographic and Health Survey 1993-94". NIPORT, Mitra and Associates, and Macro International Inc.

PIACT, Bangladesh. 1989. "A Qualitative Study to Improve BAVS Program". Unpublished.

Rob, U. and G. Cernada. 1993. "Fertility and Family Planning in Bangladesh". The Journal of Family Welfare 38(4): 53-64. 


\title{
Role of Male as the User of Contraceptive Methods
}

\author{
Dr. Abu Jamil Faisel* \\ Dr. Jahiruddin Ahmed ${ }^{* *}$
}

Paper Presented at the Workshop on Male Involvement in Family Planning: A Challenge for the National Program. Jointly organized by NIPORT, GTZ, AVSC and the Population Council. Dhaka, June 25-26, 1996.

* $\quad$ Country Representative, AVSC International, Dhaka, Bangladesh

** Director, MCH Services, Directorate of Family Planning

Introduction/Background: 
World wide it is found that one-third of all couples using family planning rely on a male method i.e. condoms, vasectomy, withdrawal or periodic abstinence ${ }^{1}$. For withdrawal, abstinence and condoms men has to participate fully. Regardless of which partner actually uses a family planning method, the man often has a major say in reproductive decisions.

According to the 1993-94 Demographic and Health Survey $^{2}$ of Bangladesh $55 \%$ percent of husbands versus $45 \%$ of currently married women said that they were currently using a method of family planning at the time of the survey. The principal methods husbands report are the pill $23 \%$, female sterilization $9 \%$, and periodic abstinence $8 \%$. Contraceptive use among husbands is higher in urban than rural ares (63\% Vs. 54\%). It is also highest among husbands in Khulna and Rajshahi Divisions and lowest in Chittagong and Dhaka Divisions. Use of family planning increases sharply with education level, from $49 \%$ of husbands with no education to $65 \%$ of those with secondary education or higher.

Further the DHS report indicates that the use of condoms and male sterilization is each one percent higher as reported by husbands than as reported by wives. Use of withdrawal is slightly lower as reported by husbands than wives. Husbands appear to be misinformed about the use of periodic abstinence; $8 \%$ of them say they are using the method, compared to only $6 \%$ of their wives. Again, most of the difference is due to wives who say they are not using any method.

The use of the following contraceptive methods requires male participation or cooperation and their worldwide use numbers are pretty big :

- Condom are used by an estimated 46 million men.

- Voluntary male sterilization (vasectomy) as a permanent method of contraception are used by some 41 million men.

- Withdrawal is used by an estimated 35 million couples.

Periodic abstinence is used by 17 million users.

The use of other contraceptive methods like pills, injectable and IUD besides the one mentioned above need a strong support of the male partner/husband. The support is more required when the wife/female partner is experiencing some side effects particularly menstrual bleeding problems.

\section{Role of Males in the Use of Contraceptive Methods:}

Like other patriarchal societies of the world in Bangladesh men has a dominant role in all sphere of life. Men as the husband in a couple's life plays the key role in making all decisions knowingly and unknowingly in matters of reproduction. The husbands expect that his wife will abide by his decisions. Even the wife most of the time looks toward her husband for instructions and decisions of day to day life matters. Men have an important say in decisions about family size and use of contraceptives. It has been found in several studies round the world ${ }^{1}$ that husbands' active disapproval led women to stop use of contraceptives. Furthermore, recent research has also provided evidence from varied settings that supportive husbands increase the likelihood that contraceptive use is initiated and, once begun, continued. 
According to the Bangladesh Demographic and Health Survey of 1993-94 husbands are generally less likely than their wives to know about female methods such as the IUD and injection and more likely to know about male methods such as the condom and male sterilization. Surprisingly, wives are more likely than their husbands to have heard of withdrawal, although in one-third of the couples, neither spouse had heard of the method.

DHS has also compared the fertility preferences of husbands and wives. Overall, there is a high degree of agreement between spouses. For example, in $26 \%$ of the couples, both spouses want more children, while in $41 \%$, both want no more children. The proportion of couples in which the husband wants more children and the wife does not $(6 \%)$ is the same as the proportion in which the wife wants more and the husband does not (6\%). In $21 \%$ of the couples, one or both of the spouses is undecided about whether they want to have more children.

\section{Male as a User of Vasectomy:}

The institutions developed for delivering MCH \& FP services are built and managed in such a way that Family Planning information are generally provided to women who come for their prenatal and postnatal checkups. In addition, family planning field workers who are usually females both in the public and NGO sectors work with women. The fact that most of the field workers are women also inhibits their access to men. There are no programs to reach men in their workplaces or at home in the evenings. There are very limited opportunities for men to receive family planning information from service providers.

The family planning programs when it was started in early 1960 had only IUD and vasectomy as the two methods of choice. Gradually pill, then injectables and minilap tubal ligation were introduced. Vasectomy remained to be a popular method until 1984-85. Since then along with tubal ligations vasectomy acceptance started declining.

In 1994-95 AVSC completed a global study on vasectomy decision making ${ }^{3}$. Bangladesh was one of the six countries participating in this study. According to the findings of the Bangladesh part of the said study one of the essential steps in the decision-making process is to decide not to have more children. In that study most of the vasectomy users and their spouses had decided to have a vasectomy during their last pregnancy or after the birth of their last child. The wife became pregnant again before the couple have accepted vasectomy as the method.

Reasons given for having more children than the number planned included the desire to have a boy or girl, method failure (condom ruptured), and dissatisfaction with oral contraceptives. Some gave no concrete reason ${ }^{3}$.

In that vasectomy decision making study respondents in all groups had first heard of vasectomy from a variety of sources, both mass media and interpersonal channels. The most commonly mentioned sources were radio and health or family planning field workers. Other sources included friends and, relatives. Less common sources were books, newspaper, television, people in the village, and relatives. Only two of the men reported having first heard of the procedure from their wives. Nonusers were less likely than the other groups to have first heard of vasectomy from a service provider.

Service providers were widely acknowledged as having provided positive information on the procedure that had helped convince the men to have a vasectomy ${ }^{3}$. 
Vasectomy users and their spouses were asked what led them to decide that vasectomy was the best method for them. In response to this question, nearly all the men said vasectomy's permanency was their principal reason for choosing it. Several also mentioned their dissatisfaction with other methods as a reason for having a vasectomy. Other responses included that it is more effective than other methods, and that vasectomy is safe and risk free.

Nearly half the respondents had begun to seriously consider vasectomy one to four months before having the operation. A few had considered the operation for one week or less (including one man who had the operation on the same day he heard of it). One respondent reported having seriously considered the operation for two years.

Regarding how the decision to halt childbearing had been made in their family, the vasectomy users were split fairly evenly between those who said that it had been a joint decision and those who felt that they alone had decided. For the most part, the wives were in agreement with both the types of decision. The majority of the vasectomy users in this study reported that they had not discussed vasectomy with their wives before having the operation. One third of the wives did not know when their husband had sought information about vasectomy, and several husbands did not tell their wives that they had a vasectomy until some time afterward.

The said study was able to detect an immediate spur-to-action for one third of the study subjects. None of the men cited a pregnancy scare as a spur-to-action. The immediate spurs to have the procedure done for the Bangladeshi men included:

1. An unplanned and unwanted pregnancy combined with financial difficulties;

2. The wife developing an inability to use contraceptives;

3. The wife's health problems;

4. Talking with a vasectomized man.

The Bangladeshi men had a somewhat different experience from the men and women Mumford had studied (Figure- 1). The right side of the figure shows the sequence of events for the Bangladeshi men interviewed here. The women's responses are not included here because very few of them were involved in the decision-making process and they were not knowledgeable about how their husbands had made the decision.

In the Bangladesh context as evidenced from the Figure- 1 that the vasectomy acceptors received lot of informations from service providers which thus has an influence on their decision making. On further probing into the perspectives of the service providers it was found that only $10 \%$ of the respondents had received training in male reproductive health, but most of the services providers had seen a vasectomy performed. About three fourth of the service providers said that they discuss vasectomy with their clients.

All the service providers said that vasectomy was a good method for couples who did not want any more children. All the providers thought that vasectomy has benefits, the most important being its permanence. Only a third of the providers felt that vasectomy also has disadvantages in comparison to other methods. The three most common disadvantages cited were that the procedure may cause bleeding, that it may affect men psychologically, and that it may cause infection. Nearly all the respondents said that the husband should get the wife's consent before having a vasectomy. 


\section{Conclusion:}

The average Bangladeshi men does not want more than two children and he is already well acquainted with all the modern methods and he is supportive of their use. But men are not reached by the field worker network set up through out the country. Men has very limited access to information on different contraceptives. Although in most of the situations men are the decision makers even for reproductive issues but due to lack of information and under the influence of rumors they disapprove use of contraceptives. In the Bangladesh DHS there is evidence that wife mentioned that the husband has disapproved use of a method whereas the husband's opinion is different. This may point out that inter spousal communication on reproductive issues is very minimum or absent.

It is quite obvious that there has been no concerted efforts to involve men in family planning and other programs to improve reproductive service delivery.

New vasectomy technique of having the procedure done without the use of scalpel (NSV) is a remarkable promising method. Inspite of many advantages of NSV this method is not gaining popularity among the males.

To encourage more male participation in all reproductive health services including the use of contraceptives by themselves or by their wives will require to have a combination of the following strategies:

a. Services and male contraceptives need to be well publicized. Publicity should address men's needs and desires. Messages should emphasize that how men will benefit from using methods and how using family planning can enhance their esteem.

b. All available opportunities should be utilized at any health and family planning service delivery centers to counsel men on their reproductive responsibilities and use of contraceptive methods.

c. Male service providers should be trained to do counseling of men.

d. Satisfied users can be enlisted to promote male-oriented methods and to counsel other men. This may be particularly be important for vasectomy.

e. Service sites need to be set up to cater to the need of the men. Men should be able to obtain the services they want and when they want. Services and supplies should be readily available near to the reach of men may be at the workplace. These should be available at times convenient for men e.g. outside working hours, evening clinics etc.

f. Services for men should respect individual privacy as much as done for women.

g. All male service providers, field level supervisors and staff as FPI, MA, HA, AHI, Doctors, NGO workers and other allied private organizations may be requested to take up the job of contacting/motivating eligible males for FP services. 


\section{References:}

1. Gallen, M., Liskin, L., and Kak, N. 1986. Men-New Focus for family planning program. Population Reports series J, no. 33. Baltimore: John Hopkins University, Population Information Program.

2. Mitra, S.N., Ali, M.N., Islam, S., Gross, A.R., and Saha, T. 1995, Bangladesh Demographic and Health Survey 1993-94.

3. Faisel, A. J., Ward, V., Landry, E., and Mehta, M. 1995. Vasectomy Decision-Making in Bangladesh. AVSC International.

4. Donahoe, D. 1995. Men and Family Planning in Bangladesh: A Review of the Literature. The Population Council, Dhaka, Bangladesh.

5. Haider, S.J., and Kabir, M. 1989. Male Attitude Towards Vasectomy: A review of Psychological aspects. Association for Voluntary Surgical Contraceptives (AVSC), Bangladesh.

6. Barkat, A., Khuda, B., Helali, J., Rahman, A., Faisel, A., J., and Bose, M.L. 1994. Situation Analysis of Clinical Contraceptive Service Delivery System in Bangladesh. University Research Corporation (URC), Bangladesh. 


\section{Figure 1}

\section{Comparison of Steps in the Vasectomy Decision-Making Process in the US and Bangladesh}
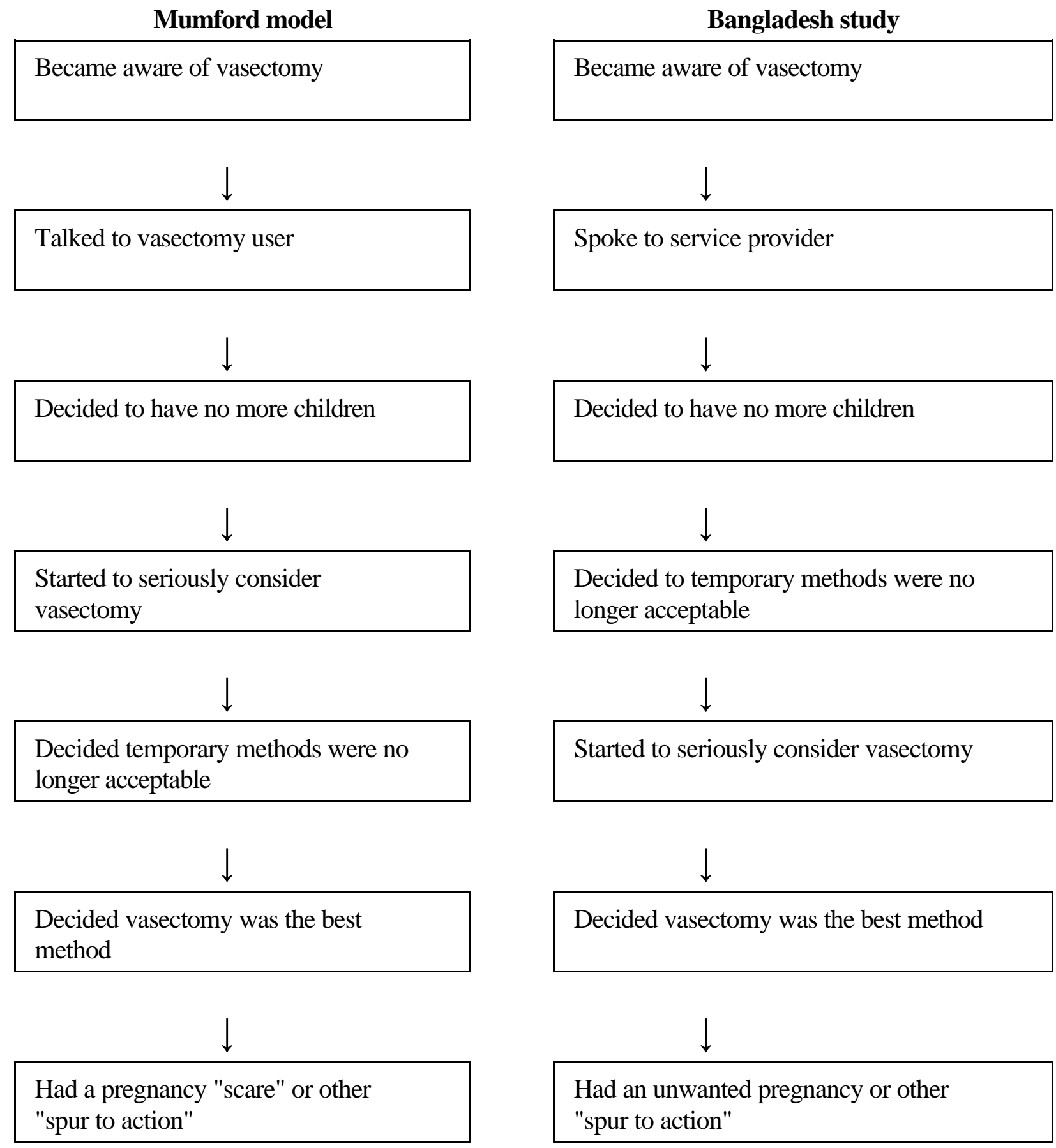


\section{Males As FP-MCH-RH Service Providers}

M. Alauddin, Pathfinder International*

AKM Rafiquz Zaman, NIPORT**

Paper presented at the Seminar on Male Involvement in Family Planning: A Challenge for the National Programme, Jointly organized by NIPORT, GTZ, AVSC and Population Council, Dhaka, June 25-26, 1996

* $\quad$ Country Representative, Pathfinder International 


\section{Introduction}

1.1 It is well known that compared to female methods, male methods for contraception are fewer - limited only to abstinence, withdrawal, condom and vasectomy. The later two are modern and the former two are traditional methods. Bangladesh family planning program began with three modern methods - foaming tablets, condom and vasectomy; condom and vasectomy are male-initiated methods and the providers were also males.

1.2 Literature on the role of males in family planning and reproductive health focused mostly, if not entirely, on their roles as users, promoters and supporters of, and in some cultures, as barriers to family planning services. In our search of family planning research, we have come across very limited literature on the role of men in family planning as service providers. This analysis is based on the limited available assessments on performance and quality of male providers in family planning services, specifically in promoting male methods.

\section{Current Situation of Male Service Providers in the Programs}

2.1 The Directorates of Family Planning and Health, NGOs, private sector and autonomous organizations that are engaged in the implementation of the national family planning, $\mathrm{MCH}$ and reproductive health program have both male and female service providers. Several categories and cadres of male staff are involved in such services as distribution of non-clinical contraceptives, administering clinical contraceptive services, counseling and information and education. In this paper, we are focusing our analysis on the direct providers - doctors and other staff in the government, NGOs, and private sectors and to a limited extent, non-program providers at the community levels.

\section{Male Doctors/Physicians}

3.1 In the Family Planning Directorate, there are 1,092 sanctioned positions for doctors; a total of 881 doctors - 752 male and 129 female are currently in position . Of the 881 doctors, 250 Medical Officers - 130 male, 66 female have recently been placed at the UHFWCs . Seventy to eighty percent of the $\mathrm{MO}(\mathrm{MCH}-\mathrm{FP})$, $\mathrm{MO}$ (Clinic), $\mathrm{AD}(\mathrm{CC})$ and $\mathrm{MO}(\mathrm{CC})$ are trained in sterilization. However, it is not known if they all of them have training in non-scalpel vasectomy. Almost all of the $\mathrm{MO}(\mathrm{FW})$ placed at the FWCs are yet to be trained in sterilization. Their training program is underway. But no information is available as to which service site has trained doctors and which site does not have trained doctors. However, it is reported that at least one doctor trained in sterilization, whether of Family Planning (MOMCH-FP) or of Health (THFPO) is available at each THC. Besides, sterilization services are available through FPCST Mobile Team.

3.2 In the Health Directorate, there are almost six thousand physicians; they are distribution by male-female is not available. However, we know that at least three-fifths of them are males. The THFPOs, almost of whom are males, have the relevance and responsibility of offering family planning, $\mathrm{MCH}$ and reproductive health services. Most of them, if not all, have received training in sterilization. 
3.3 In the family planning NGO sector, 71 full-time and 20 part-time male physicians are providing FP-MCH-RH services from NGO-run family planning clinics.

\section{Male Staff/Workers}

4.1 In the early days when the government program was initiated, during the period 1965-75, male organizers at the union level worked as motivators for family planning services. The part-time male organizers, in addition to recruiting clients for vasectomy, distributed condoms for male users. The positions of male organizers were abolished in 1975. However, in recognition of the role of men in family planning, the Directorate of Family Planning recruited full-time 4,500 male FPAs who are now redesignated as FPIs. The role of the FPIs was envisaged as motivators of male clients and promoters of knowledge, attitude change, and practice of family planning methods among males. The role of FPIs, however, was changed from motivating males to supervising female FWAs.

4.2 Another cadre of staff in the FP Directorate is the Medical Assistants (MAs). There are 2,500 sanctioned posts of Medical Assistants - one post each at Family Welfare Centre/Rural Dispensary. Of the currently positioned 2300 MAs, 1995 are males. The male MAs motivate male for male methods and provide contraceptive Injection at FWCs and RDs.

4.3 In the Health Directorate, there are 18,579 Health Assistants; of them 14,381 are male and 4,198 female. There are 1,309 HIs in place against 1,398 sanctioned posts and 3,875 AHIs in place against 4,200 sanctioned posts. All the HIs are males; no data on male-female distribution of AHIs is available.

4.4 In the NGO sectors, there are 503 male supervisors (equivalent to FPIs) and 430 full time and 17 part-time male workers to provide family planning services including IEC. The supervisors help female fieldworkers in motivational activities during household visits, participate in community meetings, educate and motivate the husbands of the eligible couples and distribute contraceptive methods in the absence of fieldworkers.

4.5 According to UNFPA-VHSS study (1989-90), there were 177 voluntary organizations affiliated with VHSS. Out of them, complete information about male and female workers were available for 169 NGOs who employed a total of 51,599 workers including paid and unpaid volunteers. About 60 percent of all workers in these organizations were males. Some big NGOs had all male workers - CARITAS employed 11,047 male workers and volunteers; World Vision employed 933 male workers. NATAB had a work force of 8,565 workers of whom 75 percent were males. Similarly Rangpur-Dinajpur Rural Services employ 1,772 workers of whom 75.5 percent are males.

4.6 The male workers in those organizations shared work with their female colleagues in such activities as providing health and nutrition education, registration of pregnant women, holding community meetings, motivating for family planning, providing referrals for clinical methods, promote breastfeeding and weaning food and provide/organize immunization for children and women.

\section{Private Sector Providers}


5.1 Social Marketing Company is the largest provider of pills and condoms in the private sector. SMC has 40, 000 pharmaceutical outlets for sale of condom pill and ORS; and another 80,000 non-pharmaceutical outlets - grocery shops and kios for sale of condoms and ORS. Sellers of these pharmacies, grocery shops, and kios are all males.

\section{Non-program Providers}

6.1 The program induced some non-program providers to become involved in the program. The GOB introduced in 1976 a system of referral fee to refer clients seeking sterilization. This system induced self-employment for some male agents who recruited clients for vasectomy. The referral system was abolished in response to the issue of coercion. Some observers think that withdrawal of referral fees might have negative effect on sterilization acceptance.

6.2 Village Practitioners who are males and estimated at 60 to 70 thousand in Bangladesh reportedly play significant role in providing family planning services to the villagers. Health practice is the secondary work for the Village Practitioners who are cultivators and businessmen, in most cases. Most of them (76 percent) had knowledge of most of the modern methods; 58 percent were users of family planning. After training, the VPs were actively participating in FP-MCH services particularly in distributing contraceptives and providing referrals. The evaluators (Rahman and Mahmud, 1985) found that the VPs contributed 37 percent of the total performance of family planning in the sample Thanas.

6.3 Community leaders, volunteers, satisfied clients, friends, relatives and neighbors are most important source of information. Male leaders generate social support for family planning. Male's support women's decision for family planning and in some cases be even direct help, e.g. husbands buy contraceptive pills for their wives and provide familial support in their wives empowering process. It is also, however, true that there are male resistance to empowered women or in women empowering program and process.

\section{The Challenge}

7.1 There are more males than females across the health and family planning programs - from national down to the field level. Leaderships of the health and family planning program lie with males - policy makers, program managers, researchers, and a large number of service providers are males. And men's favourable attitude to family planning is also very high. Yet the level of use of modern methods among males is very low - hardly 5 percent (DHS,1994). The 3.6 percent condom use and 1.1 percent vasectomy acceptance poorly compare against the current Fourth Five Year plan target of 18 percent condom use and 7 percent vasectomy acceptance. The challenge of achieving replacement level fertility cannot be reached without more outcome oriented roles of the providers, and the active participation of men in the program, both as family planning users and as supportive partners for utilization of primary health care services for the family.

\section{Issues and Recommendations}


8.1 Improving the performance on male methods is not of any single factor equation. It requires a coordinated multi-level efforts by all the sectors of the program.

8.2 There are large number of male providers in various sectors of family planning program government, NGOs and private sector to provide family planning services. In the family planning program, there are more than seven thousand field level staff (FPIs, MAs, and family planning NGO male staff. In the Health Directorate, there are 14,381 male HAs who have direct contact with people at the grassroots level. Besides, there are large number of male workers employed by the NGOs engaged in rural development activities. Added to these field level staff, there are at least 1,000 male doctors in the Directorates of Family Planning, Health, and in NGOs. These doctors have training in sterilization.

8.3 If each male field staff recruits one male for vasectomy, there will be more than 20,000 vasectomies done in a month, which is 20 times more than the national family planning performing in a month. The potential is enormous. We know very little about the extent of field level male workers/staff efforts in this regards. Whatever data are available suggest that most of the male workers do not do motivational work, only a few promote and talk about male methods, specially vasectomy (Mabud and Sabir, 1986). Less than 1,000 vasectomy performed per month in 1995 confirms very low inputs by the grassroots male workers of the program.

8.4 Some of the current and potential family planning clients, both male and female (about 1,000 participants) who recently attended seven workshops held at the thana level brought further evidence that there was lack of male-to-male motivation activity for male methods. There is no counseling program for the males. Available assessments (Rahman and Rahim, 1984; Ahmad, Shamsuddin. 1994, Ahmed, et al. 1996) reported gross underperformance of the male staff - FPIs, MAs, HIs, AHIs, HAs of the Directorates of Family Planning and Health in promoting family planning among males. Although family planning NGO contribution is appreciable high (as per MIS Unit, NGOs contributed 71 percent of the sterilization performed in the month of February 1996), their level of performance is low. Also the large number of male NGO workers in health and rural development programs do not seem to utilize their full potential to promote vasectomy acceptance and condom use.

8.5 New recruitment of additional male motivators is perhaps not needed; the currently available number of program male staff is large enough; if they undertake only a minimum effort of each one motivating/educating/counseling an appropriate male client per month for vasectomy, they can make a significant contribution to the performance outcome.

8.6 Studying specifically the decline in vasectomy (Kabir and Hiader. 1989) concluded that "Changes in the level (lower) of acceptance of vasectomy can often be tied clearly to program actions". The program needs to assess its male staff performance in family planning and determine action in terms of performance goal for individual staff and monitor their progress. Lack of clearly measurable assigned goals for individual staff is reported to be a serious obstacle in high performance by employees (Miyan, 1985). Even in the face of declining performance in sterilization, there is evidence of significantly high performance because of strong program action (EEU, 1994; BRAC, 1995). BRAC in collaboration with the District and Thana FP officials organized 268 sterilization camps in six months, during June - November, 1995 in Nilphamari District and performed 4,415 tubectomies and 233 vasectomies.

8.7 Lack of an effective training constraint doctors performance of vasectomy. Most of the male 
doctors recently placed at the UHFWCs have not been trained. The training programs in the planning process. Non-availability of clients for practical skill training is a serious limitation for effective training. Vasectomy performance has decreased so much that less than 1000 cases per month were done in 1995. This creates a vicious cycle of non-availability of clients for training, and there by there is lack of trained providers. Training program in collaboration with NGOs may solve some such problems. For example, BRAC through its facilitation program can assist in GOB Doctors Training Program in the selected districts of Rajshahi, Dhaka and Sylhet Division. This training, however, needs to be organized at locations where clients are available for practical training. In 1995, during June-November, an average, 735 tubectomies and 39 vasectomies were performed per month. If training is held in Nilphamari at the GOB-BRAC organized camps, there would be a flow of vasectomy clients for enhancing the practical skill of trainee physicians.

8.8 A fully functional personnel data base for the Directorate of Health and Directorate of Family Planning is a prerequisite for effective staff management and monitoring of their performance; it is yet to be in place. The individual CAs have the personnel data for the NGOs they support. But they do not have a consolidated personnel data base for the family planning NGO sectors as a whole. As a consequence the program do not know who is trained in what skill and when; which service site has trained doctors and which site does not have trained doctors. The data base is being currently created; when this is done, thanas without trained doctors should be identified, doctors need to be trained and placed on a priority basis.

8.9 The performance data are compiled at the central MIS in Dhaka. The monthly MIS report goes up to District level. No standardized and uniform system exists and followed by the District level officers to share MIS data with and get feed back from TFPOs. Even if the MIS data are shared with TFPOs, the thana level male performers do not know their relative position compared to performers in other Thana. Even if they know, they will know only relative position for CAR, not for any specific method, e.g. vasectomy. Performance analysis by Thana and by method, and also by availability and non-availability of providers will provide better program guidance to the local managers. It will even be better, if method-specific performance can be compared against the set goals for each Thana and each provider.

8.10 Physicians do not recruit clients themselves; they are fed with clients through a referral system. But the referral system is not effective. On one hand, the fieldworkers do not seem to talk about all the methods available, they talk only about those methods that they themselves can supply and do not have to refer anywhere which involve their time and money. Further, in some cases, the referrers themselves may perceive non-availability and poor quality of services at the receiving end of the referral system and do not feel it ethical to refer clients, on the other. All service sites do not have trained male physicians to offer male sterilization services. The URC/B conducted 1994 Situation Analysis of Clinical Contraceptive Service Delivery System found that many service points were not ready to offer vasectomy, particularly NSV, and no information was provided in any service points about male methods (Barkat A. et al, 1994).

8.11 Poor quality of services affect performance; more than one-fourth (28 percent ) of the clients were not provided with bed facility; they were kept on the floor for paucity of beds. Nearly one-fourth (24 percent) of the clients did not receive any followed up services (Miah and Rahman, 1987). The other critical factor, as reported by workshop participants that affect prima faci quality is that in many places doctors do not reside at service station (Pathfinder, 1995). The clients perhaps feel scared, should they need any emergency care, they may not find doctors at the service site. 
8.12 The Health Directorate has the largest number of male workers at the field level. The National Steering Committee recommended for creating a family planning cell in the Health Directorate. The Health Directorate should act on the recommendation in the context of its potential for providing for family planning services in general and for serving men for family planning and prevention STD, in particular.

8.13 Even though very small proportion, only 1.6 percent of the clients receive services from private clinics/doctors; but we do not know who they are and what are their organizational or clinic affiliation. We need to identify those clinics and their doctors who offer family planning services in the private and autonomous sectors and assess the feasibility of their additional contribution to family planning services.

8.14 Pharmacists who are all males were found effective as providers but not as instructors (Davis, 1985). Husbands were found effective as providers of pills as well as instructors. The users of commercial pills depended mostly upon the husbands for instructions. The pharmacists should be so trained as to train husbands to be good instructors to their wives use of pills.

8.15 Clients perceive three interrelated concerns in accepting vasectomy. One, concern of the individual males involved in the acceptance of sterilization - there is a fear of loss virility - sexual power; Two, familial concern - wives object to their husbands accepting vasectomy because wives fear that in case there is loss of workability for their husbands and consequently if they can not do heavy work, their family will suffer; Third, individual's perception of how society view acceptance of vasectomy - vasectomy is still socially looked down upon (Pathfinder, 1995).

8.16 There are very convincing evidence to demonstrate that these perceived concerns are not well grounded. Most (87 percent) of the vasectomy acceptors perceived that their relatives, friends and neighbors had shown good attitude towards their acceptance of sterilization. Majority (60 percent) of the acceptors even perceive that the religious leaders of the community had no negative attitude towards their acceptance of vasectomy; only a small proportion of clients 17 percent perceive the religious leaders had negative attitude towards them (Miah and Rahman, 1987). Appropriate IEC materials need to be developed based on these research findings and dispel the unfounded perception of the potential clients. Involvement of Village Practitioners as male-to-male counselor may enhance acceptability of male methods.

8.17 Community involvement is considered highly significant in promoting family planning services. But the local leaders perceive that the local officers do not encourage public representatives' involvement in the program. Despite of a clear policy of local level involvement, the FP-MCH programs do no emphasize local social organization and institutions' participation (Pathfinder, 1995). An evaluation of the performance of the FPIs reported unsatisfactory performance on community level activities, such as ,organizing monthly meetings and appointing depotholders reported unsatisfactory (Rahman and Rahim, 1984). The local committee meetings in most cases are not called and local decisions are not implemented (Pathfinder, 1995).

8.18 Men are not well informed about female methods and reproductive health services to be supportive to their wife's decision to use a family planning method. In some case, men do not like their wives to accept IUD because of the apprehension that it may cause discomfort in sexual relationship. Husbands, in some cases, were found to be less positive regarding the necessity of treating emergency obstetric complications (Barkat et al 1995). Men need to be well informed 
about the health needs of their wives, about how female methods and how female methods work and how best they can extend their support through their own behavior change.

8.19 Women also play important role in men's decision-making for utilizing STD treatment services. During January-December, 1995, 640 clients came to a Family Planning NGO Clinic for family planning/RTI services; of them both spouses of 94 couples were treated. In these cases of RTI treatment, wives played a key role in bringing husbands to the clinic for treatment (Pathfinder, 1996). Thus wives can also play a role in husbands' health decision.

8.20 FWAs have the extensive experience of recruiting and referring vasectomy clients. FWAs should be studied to find out what constraint them in educating and referring male clients who have completed their family size for vasectomy. Field level action plan could be developed based on the findings of such study.

8.21 Effective first of October 1995, the amount of compensation for wage loss, cost of food and transportation has been raised from Tk. 175 to 275 for sterilization clients, both tubectomy and vasectomy. The FWAs will be reimbursed Tk. 50 per journey accompanying sterilization clients beyonds 5 miles of her place of work. Provision has also been made for improving the quality of surgical apparel to be provided to the sterilized clients. A study should be conducted to assess the impact of these interventions.

8.22 There are large number of male providers in the health and family planning in all sectors government, NGO, and private sector. To what extent and how well they are working for promoting male methods is an appropriate question to ask. Available data and knowledgeable observers conclude that gross inadequate compliance to performance of tasks seems to be a critical management issue. Effective staff utilization and getting results from them is the first order of challenge the managers of the health and family planning program need to address. There is a tremendous unexploited potential for male-to-male education and counseling for promoting male methods, both by government and NGO program male staff and by non-program satisfied vasectomy acceptors, condom users, and village practitioners. NGOs in some areas can ensure clients flow for hands-on skill training - GO-NGO collaboration is highly recommended for training physicians in sterilization in particular and other areas as well. Also GO-NGO collaboration strengthens referral and follow-up and thereby facilitate higher performance, as has been demonstrated by BRAC facilitation program in Nilphamari. IEC materials and messages should be based on the program experience and available research findings to address unfounded fear and perception.The pharmacists can play a far greater role - they should be so trained as to train husbands (who buy pills for their wives) to be good instructors to their wives use of pills. Males need to increase their knowledge about males methods to be fully supportive to their wives; so is the need for the wives - wives need to increase their knowledge about male methods so that they don't have fear of loss of their husbands workability. Thus, multi-level action is required to improve males role for effective delivery of family planning services. 


\section{References}

Ahmad, et al 1996. Assessment of the Role of HAs in Health and Family Planning in Bangladesh. Dhaka: NIPORT (unpublished)..

Ahmad, Shamsuddin. 1994. Assessment of Role FPIs in MCH-FP Programme in Bangladesh. Dhaka: ARTCOP and NIPORT.

Barkat, A. Javed Helali, Matiur Rahman, Murtaza Majid, Manik Lal Bose. 1995. Knowledge, Attitude, Perception and Practices Relevant to the Utilization of Emergency Obstetri Care Services in Bangladesh: A Formative Study. Dhaka: URC/Bangladesh.

Barkat, A. Barkat-e-Khuda, Javed Helali, Rahman, A. Faisal, A.J., Bosh M.L. 1994. Situation Analysis of Clinical Contraceptive Service Delivery System in Bangladesh, URC, Bangaldesh.

BRAC. 1995. Annual Report On Family Planning Facilitation Project funded by Pathfinder International.

Davis, John. 1985. Oral Contraceptive Distribution in Bangladesh: Husbands as Providers and Instructors, Hawaii University

DHS. 1994.NIPORT \& Mitra and Associates: Bangladesh Demographic and Health Survey.

EEU. 1994.

Haider and Kabir. 1989.

Mabud, F., M. A. Rashid and Ahmed Al Sabir. 1986. Evaluation of the Training Programme of Health and Family Planning Field Worker. NIPORT Dhaka.

Miah, J. Abedin and Muhammad Bazlur Rahman, 1987. Assessment of Satisfaction of the Sterilization Acceptors. PDEU, Planning Commission

Miyan, M. Alimullah. 1985 .Training Need Assessment of Upazila Health and Family Planning Officials. Centre for Population Management and Research (CMR), Dhaka University.

MIS Unit, 1996. Contraceptive Performance and MCH services, Dhaka: Directorate of Family Planning.

Pathfinder International, 1995. Grassroots Perspectives on Future Challenges in FP-MCH Program: An Integrated Report on Seven Thana Level Workshops. Dhaka.

Pathfinder International, 1996. RTI Performance Report.

Rahman, M.B. and M.A. Rahim. 1984. An Evaluation of The Performance of FPAs and FWAs. External Evaluation Unit, Planning Commission, Dhaka February 1984, EEU Series no 23 in Waliullah, S. and F. Mabud. 1995. Population and Family Planning Research Bangladesh: An Annotated Bibliography, Dhaka: NIPORT. 
Rahman, S. and T. Mahmud. 1985. Role of Village in Family Planning Service Delivery System, in Population and Family Planning in Bangladesh An Annotated Bibliography (Third Volume) Dhaka, NIPORT, Page 90.

Rahman, Shafiqur and Tasmina Mahmud. 1985. Role of Village Practitioners in Family Planning Service Delivery System, Population and Family Planning Research in Bangladesh: An Annotated Bibliography (Third Volume), NIPORT.

UNFPA-VHSS Study. 1989-90. Non-Government Organizations in Health and Family Planning: Bangladesh. 


\title{
Highlights of Regional Male Involvement Family Planning Programs
}

\author{
Nancy J. Piet-Pelon ${ }^{*}$ \\ Ahmed-Al-Kabir ${ }^{* * *}$
}

Paper Presented at the Workshop on Male Involvement in Family Planning: A Challenge for the National Program. Jointly organized by NIPORT, GTZ, AVSC and the Population Council. Dhaka, June 25-26, 1996.

* $\quad$ Consultant, The Population Council, Dhaka, Bangladesh

** Sr. Regional Program Advisor, AVSC International, Dhaka, Bangladesh

The national family planning programs in the Asia region include many success stories. The 
Republic of Korea, Japan, Taiwan, Thailand and the city states of Hong Kong and Singapore have made remarkable achievements in reducing population growth through accessible and affordable family planning services, coupled with remarkable economic and educational development. Indonesia, Bangladesh, and India are achieving their national goals in family planning and each has a Contraceptive Prevalence Rate (CPR) which exceeds 40 percent. Sri Lanka nearly achieved replacement level fertility before the civil disturbances of recent years slowed their steady progress. While not as successful as their Asian neighbors, both Nepal and Pakistan have overcome both terrain and cultural barriers to deliver family planning services to an ever-increasing number of acceptors.

Yet, for all the success of the Asian family planning programs, it is impossible to point to one which has consistently met men's family planning needs. Women have been the primary focus of family planning programs. The reasons are pragmatic: "... they are the ones who become pregnant, most modern contraceptive methods are for females and, consequently, family planning services have been offered in MCH/FP outlets" (Green et al., 1995). This made sense in the past, and still does if family planning is the lone objective of a health service. But with increasing awareness and concern about the role men play in the transmission of STDs/HIV and AIDS, marginalizing men in family planning and reproductive health services is not appropriate. Ignoring men's needs greatly increases their health risks, as well as those of their partners.

In the Programme of Action of the International Conference on Population and Development, the essential role men share in the reproductive health of women is defined. The emphasis of the international definition is on gender equality. As the document states:

"...Men play a key role in bringing about gender equality since, in most societies, men exercise preponderant power in nearly every sphere of life, ranging from personal decisions regarding the size of families to the policy and programme decisions taken at all levels of Government."

In addition to male programs concentrating on the promotion of gender equality in all aspects of life, the ICPD document suggests programs be developed with an objective "...to encourage and enable men to take responsibility for their sexual and reproductive behavior and their social and family roles." To reach this broad objective "...Special efforts should be made to emphasize men's shared responsibility and promote their active involvement in responsible parenthood, sexual and reproductive behavior, including family planning; prenatal, maternal and child health; prevention of sexually transmitted diseases, including HIV/AIDS; prevention of unwanted and high-risk pregnancies; shared control and contribution of family income, children's education, health and nutrition; and recognition and promotion of the equal value of children of both sexes."

This paper will (1) define the role of men in family planning; (2) review the history of program approaches to men in their multiple roles as partners, national program managers, service providers, and researchers; (3) describe some current model programs; and (4) provide recommendations for future male programs. The emphasis is on family planning and the successful inclusion of men in family planning services. However, the role of men in the context of reproductive health is a critical question for the future which cannot be ignored. Thus, this paper will comment, where appropriate, on programs which have gone beyond family planning in reaching men concerning reproductive health and rights. 


\section{(1)}

\section{Defining the Role of Men in Family Planning Matters:}

Every man needs family planning. While he avoids the physical ordeal and risk of child birth, he bears other responsibility related to his progeny. The economic burden of rearing children is only one that is either solely or partially his. He also shares the vital task of nurturing his children in cultural and societal values. He suffers the loss of his companion and mother of his children if his partner dies in child birth. He lives with unmitigated stress if she is debilitated by a continual cycle of pregnancy, birth, and lactation. Thus, it is essential that men are enabled to become active partners in family planning.

Some would argue that the most important role of men in family planning is as the supportive half of a contracepting couple. There are no indicators for "supportive" that are advanced by research. However, it is possible to assume that being supportive includes a positive role in decision making. Couples can either make a joint decision or a man can allow his partner to make a decision which suits her. Support may also include being the conduit of information about methods for the partner or purchasing those methods (i.e. pills, condoms and other marketed contraceptives). Involvement in overcoming problems with side effects or complications of method use is also a supportive role for male partners. This may include emotional support for minor complications or financial/logistical support for a clinic visit for side effect management. Supportive partners educate themselves about methods, both male and female ones, in order to help make informed decisions.

A second role for men in family planning is as acceptors themselves. Worldwide about 35 percent of current users rely on methods which require active male participation -- vasectomy, condoms, withdrawal and periodic abstinence. Men who are committed to sharing responsibility and to a planned family size may use a male method to meet mutually agreed upon family size aspirations.

Beyond being family planning acceptors or supportive partners of acceptors, men have several other critical roles in family planning programs. As program and policy managers, men have great influence on family planning programs. They make key choices. Among these are: how funds will be allocated; the gender of field staff, as well as the definition of their tasks; the types of clinics and choice of methods available at each level of the service delivery program; decisions to seek, hire and train female clinicians to work with women; and regulations which govern method choice. In these roles they exert both positive and negative influences which directly effect access to family planning for women and their partners. In the Asia region, the majority of program and policy managers at the top levels of national programs, are men.

Another role of men in family planning is as providers who determine what services couples or individuals receive. Male service providers who are empathetic to the needs of the contracepting couple can positively influence male clients. They can either provide information about male methods or educate the male partner to his supportive role when the choice is a female method. Over the years many programs have encouraged the employment of female service providers and front line workers. This is particularly true in conservative countries where women's status limits their interaction with men. Unfortunately, some programs have nearly eliminated male service providers. This has resulted in potential male clients failing to locate a safe environment where they can obtain accurate information and services.

Provider bias does effect male services. As one UNFPA report on male involvement summarizes: 
"The assumption of many health care providers that men are uninterested in taking responsibility for family planning has become a self-fulfilling prophecy. Most reproductive health/family planning service delivery systems are almost entirely oriented to women and provide little or no information about male contraceptive methods. Health workers are sometimes poorly trained in counselling men about safer sexual practices and male methods and may communicate negative rumors about them. (Green et al., 1995)

Researchers influence the future of family planning through their studies of current programs and the roles that men have in these. The inclusion of men in surveys such as the popular Demographic and Health surveys has provided useful information on social behavior, male partnership in family planning decision-making, and point to areas where men are neglected by services. Situation analysis of clinical services in different countries in the region have been conducted. The results indicate that services reach women effectively but fail to reach men. There are two consistent reasons for this: the service providers are women who are comfortable with women clients; and, male methods or IEC for men are not consistently available.

Contraceptive research influences the future choice in methods. In the past several decades, research has concentrated mainly on the development of new female methods -- starting with the oral pill and various IUDs and continuing with the injections and implants. The newest work in female contraceptives is concentrated on dual protection from pregnancy and RTIs/STDs through the use of female condoms and microbicides. The search for male family planning methods has not been as active. There are two commonly cited reasons for this: (1) the fertility of the female reproductive system is easier to impede, and (2) as women are at risk from pregnancy preventing their risk is an essential health intervention. In China recent research on male methods includes the development and dissemination of non-scalpel vasectomy (NSV) and the use of temporary methods for vasectomy. Research to develop an injection to immobilize sperm in England has recently been announced. While still at an early stage of trials, initial results are promising.

Historical Approaches to Men and Family Planning:

Prior to the development of modern methods of birth control, men had to be actively involved in limiting family size through the use of withdrawal, periodic abstinence and condoms. Withdrawal is a method which is chronicled since early history, while condoms were first used more than 400 years ago. When oral contraceptives and IUDs were first introduced, their use began to eclipse the traditional male methods -- except for vasectomy.

In the 1950s and 1960s, South Asian countries launched national family planning programs using a clinic-based approach. This was gradually supplemented by a community-based system which brought supplies and services nearer to the potential clientele. The sterilization programs in the region depended on a combination of mobile and static services. Bangladesh, Nepal, India and Pakistan widely used mobile sterilization facilities from the late 1960s. Both Nepal and Pakistan are still using the mobile approach, while Bangladesh and India have adopted policies which favor static approaches. In many Asian countries in the early decades of national family planning program efforts, men were "targeted" through vasectomy campaigns and services. Many men were sterilized from the 1950s through the mid-1980s. The accomplishments of these programs were to provide needed services to tens of thousands of men. Unfortunately, there were also abuses when a motivational rather than informational approach emphasized an immediate reward rather than a long-term goal of limiting family size. Thus some men focused their decision on what they would 
receive (e.g. a radio or a compensation payment) rather than the vasectomy and its consequences. This inappropriate emphasis led to abuses of informed consent and, in some cases, regret that the vasectomy had been done. Most programs halted incentives for sterilization and increased emphasis on informed consent and quality services. Performance of vasectomy has never again reached the levels of the mid-eighties in the sub-continental programs. In recent years, only India still performs a substantial number of vasectomies while in Bangladesh, Nepal and Sri Lanka the performance of vasectomy has fallen to negligible numbers.

In spite of the low numbers of new acceptors for vasectomy, the method continues to have a strong impact in the Asia region. Worldwide approximately 42 million couples of reproductive age ( 5 percent of all married couples) use vasectomy as a contraceptive method. Vasectomy is a major family planning method in six developed countries -- Australia, Canada, Great Britain, the Netherlands, New Zealand and the United States -- and three developing countries -- China, India and South Korea. Sterilization users are remarkably concentrated geographically in the developing world, with China having nearly half of all sterilization users and India having over a fourth (Ross and Frankenberg, 1993). 
TABLE 1: Worldwide Use of Vasectomy as of 1991

\begin{tabular}{|c|c|}
\hline Region & $\%$ of Couples Relying on Vasectomy \\
\hline China & 8 \\
\hline India & 7 \\
\hline Other Asia and the Pacific & 1 \\
\hline Latin America and the Caribbean & 0.7 \\
\hline Near East and North Africa & Less than $0.5 \%$ \\
\hline Sub-Saharan African & Less than $0.5 \%$ \\
\hline All Developing Countries & 5 \\
\hline \multicolumn{2}{|c|}{ Developed Countries } \\
\hline Australia and New Zealand & 13 \\
\hline Europe (includes Eastern Europe and & 3 \\
the F.S.U) & 13 \\
\hline North America & 2 \\
\hline Other Developed & 5 \\
\hline All Developed Countries & \\
\hline
\end{tabular}

Source: Liskin et al., 1992

At the same time, the distribution of condoms has increased in all the Asian countries. This male method has become a major sales product in social marketing programs. These companies, side-by-side with commercially marketed condoms, have increased the outlets for condoms. Information about condom use is available from the same source, making it possible for men to do one stop shopping for information and service. Brand recognition for the social market condom products is high. Nirodh, Raja, Panther are used as generic terms for condom in India, Bangladesh and Nep al respectively. Thailand's promotion of condoms is perhaps the most innovative in the Region due to the creative approaches of PDA and its leader, Dr. Meechi. Fifteen percent of current users in Hong Kong are condom acceptors. This is one of the highest rates in Asic (Green et al., 1995)

Condom promotion has gone beyond family planning use. Of particular importance with the advent of HIV/AIDS and increasing STDs, the use of condoms as a prevention of infection is essential. Again, 'l'hailand has been "l leader in the promotion of condoms for infection prevention.

In addition to services, male opinion leaders have been involved in family planning since the inception of national population program efforts in the Region. Particularly when family planning was initially promoted, garnering the acceptance of opinion and community leaders was essential for program success For example, in the decade of the $70 \mathrm{~s}$ considerable time and effort was spent by the Indonesian National Family Planning Coordinating Board (NFPCB or BKKBN) to reach religious leaders of all faiths and encourage their support for the family planning inovement. The Council of Ulamas issued statements, based on their interpretation of the Koran, which favored the concept of spacing. 
They also made positive statements about the use of certain modern methods. ${ }^{1}$ Though Catholicism is a minority religion in Indonesia, the Catholic bishops declared family planning decisions a "pastoral question", a term which enjoins an individual priest to counsel couples about all their family planning options, not simply those encouraged by the Catholic doctrine. ${ }^{2}$ The Council of Protestant Churches in Indonesia managed a major responsible parenthood program providing services through a network of Christian hospitals and, at a national level, being a member of the National Family Planning Coordinating Board (NFPCB/BKKBN). While not labeled "male involvement", all of the religious leaders were men and their influence was both in their constituencies and in their individual families.

Other countries also made positive use of male opinion leaders. Through government and NGO channels, as well as other community organizations, w ord about family planning was disseminated. At the national policy levels, Prime Ministers and Presidents, lent their support to family planning programs through the Declaration of World I eaders of 1967. Asian leaders are particularly known for their support of family planning programs, often making the success of this program a comerstone of the country's development.

\section{Model Programs Reaching Men}

In an ideal male involvement program, there would be policy statements and national goals which balance the needs of men and women and provide information and services for both in equal facilities. This has not yet happened in the Region. National policies rarely highlight or separate the needs of men. Instead policies are written with couples and their family planning goals and responsibilities as a focal point

Model programs need to be based on several premise, which have been defined through research in the Asia region:

- Men need to be involved in family planning. In Muslim societies, which are male dominated, men need to be involved in family planning. This premise is supported by (1) studies in which women report or imply that family planning use/decisionmaking is determined by their husbands; (2) studies that show that men who are knowledgeable about family planing express an interest in controlling the number of children they have; and (3) studies where involving men has made, or appears to have made, a difference in couple and/or individual tamily planning acceptance and/or community acceptance.

Involvement of recognized local leaders is the key to a successful program. It is essential to ensure the involvement of recognized local community and religious leaders, particularly in less affluent and more tratitional areas. Because men usually

\footnotetext{
1 The Council of Ulamas refuled to sanction sterilization. To date, this method is not an official method of the national family planning program although the BKKBN has made every effort to provite the means for the services to be accessible through equipping service points, paying compensation paym nts and supporting the training of service providers throrgh other organizations.

${ }^{2}$ The only other Catholic church to take a similar stand in the decade of the se: enties was the Mexican church. The Bishops were called to Rome to defend their policy to the Vatican which he'y iccomplished successfully.
} 
occupy traditional leadership roles, their support of family planning can reduce opposition and allow their followers to make their own decisions. Their failure to support the program often has the opposite effect creating many obstacles for acceptance.

- Men tend to be aware and to approve of family planning in general. The literature shows that men tend to be increasingly aware of the small/family concept which has been portrayed extensively in the media. They occasionally mention the health of the mother as an important reason why they would practice, or encourage their wives to practice, family planning. They report a desire to provide a better economic standard for their children, particularly through educational opportunities. They are aware that a large family poses a constraint to that goal.

$\square \quad$ A strong relationship exists between interpersonal communication and family planning use. It appears that IEC efforts aimed at improving interspousal communication have been successful. Interventions have shown the importance of teaching men about female as well as male methods. This seems to lead to an increase in interspousal communication and hence to rreater family planning acceptance. The literature shows that an increase in family planning acceptance also coincides with exposure to others, especially peers, who are ware of family planning. A logical implication is that the partner's familiarity with various methods, as well as with sexuality and reproductive health, could increase interspousal communication and family planning acceptance.

Model programs should also be based on the strengths and weaknesses, as well as the opportunities and threats (SWOT) which can effect mule programs. A recent SWOT exercise in Pakistan yielded results, many of which can be generalized to other Asian countries.

\section{Strengths for Male Program Development:}

1. A large number of male and female field $n$ orkers are available in country programs to promote male involvement activities.

2. IEC programs are expanding and have the potential to include male focused materials.

3. Facilities to train male doctors and staff are ar ailable in most countries.

4. Satisfied clients and mass media can be utilized for reaching men.

5. Both Government and NGO networks are available for male initiative programs.

6. Contraceptive methods for men are available in all programs.

7. Social marketing programs can be used for re iching men and are available in most countries.

8. Political commitment for family planning programs continues to be strong.

9. There are increasing numbers of satisfied tamily planning users whocan influence others.

\section{Weaknesses for Male Program Development:}

1. There is a lack of trained service provider for male methods, especially vasectomy services but also counselors who work with men on use of traditional methods.

2. There are misconceptions about male methods due to poor motivation, counseling and information. 
3. Male domination, social-cultural factors and religıous barriers can have a negative effect male involvement in family planning.

4. There has been no special initiative to popularize male involvement.

5. NGOs and private sector have developed/tested very few innovative approaches for male involvement.

6. There is poor or non-existent counseling for men and couple counseling often is not a practical alternative.

7. There is a lack of effective IEC for men.

\section{Threats to Male Program Development:}

1. Unwillingness and lack of commitment on the part of program managers, field workers and service providers to include men in family planning programs.

2. Continued high rates of MMR and IMR in some countries.

3. Low literacy rate in some countries.

4. Dysfunctional dynamics in the decision-making process at family and community levels.

5. Target pressure on the staff in some programs.

6. Misconceptions and rumors about family planning methods, as well as side effects and concerns about method failure.

7. Counseling and quality of services for men is poor.

\section{Opportunities for Male Program Development:}

1. Established network of family planning services, information and counseling at clinical facilities.

2. Family planning programs have already incorporated assistance from NGOs, traditional healers, private practitioners, health department staff and extension services staff.

3. Mass media can reach men in most countries.

4. There are male organization which can reach men.

5. Unmet need for family planning.

6. Increase in the prevalence of STDs, HIV / AIDS has drawn attention to reproductive health needs of men (ICPD declaration).

7. Donor support and the availability of technical resources in the Region.

8. Male doctors are available in hospitals where reproductive health centers can colocated and can be trained in male family planning methods and other aspects of male involvement.

\section{Current Use of Male Participation Methods:}

There is great variation across countries in the use of methods which require male participation. In Turkey, a predominately Islamic country, withdrawal is the most popular method used (TDHS 1994) and condom use is nearly 7 percent of all current users. In the Philippines, withdrawal and periodic abstinence are each used by about 7 percent of current users (PNDS 1993). Indonesia has a very limited use of all male methods. When CPR was nearly 50 percent only 3.2 percent of current users practiced any male method (IDHS 1991). 
Other data from Indonesia indicates that men are not involved in family planning, rather the program's considerable success is built solely on the use of female methods and on women's decision-making. Women who discontinue a method cite husband's disapproval as a reason in only 1 percent of cases. Non-users say their husband is opposed in only 6 percent of cases. It seems the Indonesia program, which is concentrated on temporary methods, is not emphasizing the male role either as a contraceptive user or as a supportive partner.

The table below summarizes the use of male methods in select countries in Asia and the Middle East.

Table 2: Current Use of Male Methods in Selected Countries

\begin{tabular}{|c|c|c|c|c|c|c|}
\hline Country & CPR & Vasectomy & Condom & $\begin{array}{c}\text { Withdraw } \\
\text { al }\end{array}$ & $\begin{array}{c}\text { Periodic } \\
\text { Abstinence }\end{array}$ & $\begin{array}{c}\text { Total } \\
\text { Male Methods }\end{array}$ \\
\hline $\begin{array}{l}\text { Bangladesh } \\
(\text { BDHS1993-94)* }\end{array}$ & 44.6 & 1.1 & 3.6 & 2.5 & 4.8 & 11.4 \\
\hline $\begin{array}{l}\text { India } \\
(\text { NFHS1992-93)* }\end{array}$ & 40.6 & 3.4 & 2.4 & 1.4 & 2.6 & 9.8 \\
\hline $\begin{array}{l}\text { Indonesia } \\
\text { (IDHS 1991)* }\end{array}$ & 49.7 & 0.6 & 0.8 & 0.7 & 1.1 & 3.2 \\
\hline $\begin{array}{l}\text { Pakistan } \\
(\text { PCPS 1994-95)* }\end{array}$ & 17.8 & 0.0 & 3.7 & 4.2 & 1.6 & 8.9 \\
\hline $\begin{array}{l}\text { Philippines } \\
\text { (PNDS 1993)* }\end{array}$ & 40.0 & 0.4 & 1.0 & 7.4 & 7.3 & 16.1 \\
\hline $\begin{array}{l}\text { Egypt } \\
\text { (EDHS 1992) }^{*}\end{array}$ & 47.1 & 0.0 & 2.0 & 0.7 & 0.7 & 3.4 \\
\hline $\begin{array}{l}\text { Turkey } \\
\text { (TDHS 1993)* }\end{array}$ & 62.6 & 0.0 & 6.6 & 26.2 & 1.0 & 33.8 \\
\hline
\end{tabular}

* Source of Information

Of the countriescited in this table, only India has a vasectomy current use rate which exceeds the other male methods. In Indonesia, Pakistan, Philippines, Egypt and Turkey, the current use of vasectomy is less than one percent.

\section{Highlights of Successful Programs in Asia:}

Pakistan is more known for its conservative societv and male dominance of all aspects of family life than for its family planning program The Basic Findings of the Pakistan Contraceptive Prevalence Survey of $1994-95$ have r'cently been published. These findings show that contraceptive prevalence is nearly 18 percent, which is low compared to most of its Asian neighbors. Of the 18 percent, about two-thirds rely on a modern method, with female sterilization and condoms being the most popular choices. Vasectomy use is limited and does not reflect in the national sample. More than half the respondent want no more children yet the majority of them are not using family planning methods to prevent pregnancy. The "Basic Findings" for 1994-95 do not include information about the attitudes of husbands toward family planning. However, the 1991 CPS records that 43 percent of husbands did not approve. This is considerably higher than Bangladesh where 8 percent do not approve of family planning (BDHS 199,3-94). 
This is not a positive atmosphere for successful male involvement, particularly for a program which focuses on male services. Yet, there are successful programs for vasectomy services. In 1987, the Family Planning Association of Pakistan (FPAP) started a male program in a clinic in Faiselabad, an industrial town in the heart of the Punjab. AVSC International provided the technical assistance and funding for the program. It took five years for the services to gain momentum but the clinic now provides an average of 60 vasectomies a month. The driving force behind the clinic is i dynamic program manager and a skilled NSV provider. These men used their person al influence to gain credibility for the male program. Their efforts were reinforced by a med ia barrage focussing on men and bearing a two-fold message: the availability of male serv ices and the clinic location. The media messages were repeatedly disseminated through rickshaw slogans, film shows, meeting with community opinion leaders including government officials and teachers, as well as industrial representatives. Traditional birth attendants were included in the information network and satisfied clients were encouraged to tell their stories to potential clients and friends. Male outreach workers were trained and provided motorcycles to extend their community reach. The service itself was provided by a physician who was involved in the information meetings. He conducted all the pre- and post-operative counseling and guided the potential clients through each ste $p$ of the procedure.

This combination of effort created a male service which now dominates the work of the FPAP clinic in Faiselabad and is being replicated in other enters in Pakistan which receive AVSC International assistance. The level of effort is intense but comparable to what has been done to and for women over decades of family planning service programs.

Pakistan is also the first country in Asia to conduct a national workshop on male involvement. Held in 1993 and supported by AVSC International and the Population Council, this workshop in the Punjab showcased the successful male frograms and charted future directions for the Pakistan male program. The current Fiw Yeir Plan includes specific goals for male services. This is the first time a five year plan doc $\mathrm{m}$. nt in Pakistan included goals for mens' services.

Vietnam is a country where centuries of equality of the sexes preceded the present Communist government. Though the economy and educition opportunities are lacking for the entire population, access is delermined by factors other than gender. Son preference continues to some extent, yet women in Vietnam are accorded a more equal status to men than in many traditional societies. They are equally liter.nte and equally in the work force. Women control much of the market economy, particularly at the petty trader level. Decades of war have also inculcated certain values in the society incluiting interchangeable roles. In the absence of men at all levels of society and in both rura or urban settings, rigid role responsibilities have blurred. Women have governed, acted as community leaders, farmed, traded, and made decisions on all family matters in the absence of male partners during wartime. In peace, it is common to see women continue as f rin ary decision-makers in many contexts.

The family planning program is a long-established one - in 1960s for the North and the 1970 s for the South. Access to modern methods has been circumscribed until recently by the United States-led trade embargo (lifted in 1994). Sterilization, particularly NSV has recently been introduced but the reach of programs using the lat st technology is still limited. 


\section{(4) Recommendations for Male Involvement Programs:}

Though it sounds simplistic, men need what women need in order to make appropriate family planning decisions. They need to have access to information and quality services which are accessible. They need to have a choice of methods offered by technically competent service providers. Of particular importance, as it is for women, men need to be treated holistically. They are not simply demographic tar sel in need of a family planning service but clients who require a variety of services.

Recommendations which are derived from successful male programs include the following list:

1. Community outreach is essential in male involvement efforts. Men need to be reached directly and individually with convenient services and accurate information. Community outreach encompasses a variety of approaches including: using community groups, field workers, CBD distribution, volunteer counselors, traditional healers, and telephone hotlines. All these can provide unformation, counseling, supplies and referral for family planning services.

2. Male focussed IEC activities are needed to improve men's knowledge of family planing, Trained male field workers should be included on the staff of static service delivery outlets or in the referral network for the following tasks:

(a) to establish links with influential community members;

(b) to distribute motivation and educational materials to community leaders, shopkeepers, indigenous health practitioner an 4 potential clients;

(c) to arrange information meetings at the centers (utilizing audio/video aids);

(d) to organize formal and informal meetings in surru unding areas to promote male methods of contraception;

(e) to arrange the distribution of IEC materials during local festivities.

3. Trained staff are crucial to male involvement programs. Training is essential to integrate male services into female-oriented settings. Many FP/MCH workers lack the requisite skills and information to assist maie dients effectively. Other staff members, even high-level managers, may be ill-intormed. Training in interpersonal communication skills is important, as well as thin ng in the delivery of quality services.

4. Use of existing facilities for male activities shoukt be a policy of all programs. Male programs should be an integral part of an agency': portfolio of interventions to promote reproductive health and should be consistent with the agency's overall mission and infrastructure. Whenever possible, heallh agencies should use existing infrastructures, such as commercial marketing netwolks, logistics systems and agencies involved with IEC programs to promote walc involvement. Private sector participation in male programs should be encour :get.

5. Men seek quality services which have the follow ing components:

(a) an array of services including general medical cart . tre atment of urological problems, sexual dysfunction, STDs and infertility; 
(b) skillful counseling which helps men articulate their concerns and health-care needs, allows them to clarify their views and make appropriate choices regarding reproductive behavior;

(c) privacy and confidentiality are essential aspects of male services - many men will travel great distances to assure they will not be recognized by neighbors or friends;

(d) technically competent clinicians who frovide the services;

(e) accessible service points with working lours and locations that are convenient for men;

(f) effective promotion through talks and home visits by field workers, bill boards, magazine advertisements, cinema slides and radio/television spots are needed to reach male clients;

(g) clinic appearance - signs, decor and c eanliness - are all important;

(h) low cost services, especially for vasectomy, make these more attractive to men.

Male programs which meet these criteria can be leveloped if their needs are accorded priority attention in national programs. 


\section{References:}

Bangladesh Demographic and Health Survey (1993-94), Niport Mitra and Associates, Demographic and Health Surveys, Macro International Inc., Dhaka

Egypt Demographic and Health Survey (1992), National Popul tion Council and Demographic and Health Surveys,Macro Systems, Inc., Cairo.

India Summary Report National Family Health Survey (1992-93), International Institute of Population Science, Bombay.

Indonesia Demographic and Health Survey (1991), Central Bure, u of Statistics, National Family Planning Coordinating Board, Ministry of Health, and Demoraf hic and Health Surveys, Macro International Inc., Jakarta.

Pakistan Contraceptive Prevalence Survey 1994-95 Basic Findings (1995), The Ministry of Population Welfare and the Population Council, Islamabad.

Philippines National Demographic Survey (1993), National St.tis' ics Office and Demographic and Health Surveys, Macro International lnc.

Turkey Demographic and Health Survey (1993), Ministry of Health General Directorate of Mother and Child Health and Family Planning, Hacettepe University 'nstitute of Population Studies, Demographic and Health Surveys, Macro International Inc., Ankura.

Green, C. P., et al. (1995), "Male Involvement in Reproductive H'-altlı, Including Family Planning and Sexual Health", Technical Report 28, UNFPA, New York.

Ross, J.A. and E. Frankenberg (1993), "Findings from Two Do ade if Family Planning Research", The Population Council, New York 


\section{Male Motivation for Promotion of Women's Participation in Decision-Making - An Important Element of Family Planning Programme}

Dr. Ahmed Al-Sabir*

Habibur Rahman**

Nazrul Islam ${ }^{* * *}$

Paper Presented at the Workshop on Male Involvement in Family Planning: A Challenge for the National Programme. Jointly organized by NIPOR T, (iTZ, AVSC and the Population Council. Dhaka, June 25-26, 1996.

* Director, (Research) NIPORT

** Associate Advisor, MIOR, GTZ/NIPORT

*** Sr. Programme Officer, Information, Documentation and Research, GTZ/NIPORT 


\section{INTRODUCTION}

The importance of strengthening women's participation in decision-making at all levels is not a new concept in family planning. But the concept has gained substantial momentum after the International Conference on Population and Development (ICPD) held in Cairo in 1994. ICPD recommendations address necessary changes in both men's and women's knowledge, attitude and behavior and other conditions for achieving the harmonious partnership of men and women. Men play a key role in making gender possible since, in most societies, men exercise preponderant power in nearly every sphere of life, ranging from personal decisions regarding the size of families to the policy and program decisions taken at all levels of government. It is essential to improve communication between men and women on issues of sexuality and reproductive health, and the understanding of their joint responsibilities, so that men and women are equ 11 p. rtners in public and private life (ICPD 1994).

\section{SITUATION OF WOMEN'S DECISION-MAKING IN BANGLADESH}

In Bangladesh, the husband is the dominant decision-maker in the family, and the wife is expected to abide by his decisions. Culturally women are not seen as and not expected to become independent persons. They are required to remain under the "protective guardianship" of successive male kinsmen at the appropriate stages of their life cycles: father or brother, husband and, eventually, son. In consequence women are often incapable of or prevented from making their own decisions (We'stergards 1983; Adnan 1988). In addition, arranged marriages and large differences in age it marriage between bride and bridegroom place a wife in a subordinate position relative to her husband at the outset of marriage (Cain 1984). Moreover, a new wife has to 'prove her worth " to her mother-in-law and other female relatives (Jahan 1975). Paramount to the consolidation of her identity and status amongst her in-laws is the socio-biological role of reprofucing the partrilineage (Chen 1986). This crucially requires her to give birth to one or more son $;$ (Jahan 1975). Any reluctance or failing on her part in child-bearing may lead to abuse and physical assault from her husband and in-laws (Sabir 1993).

Decisions about family size and the use of contraceptives by wives and their continuation also depend largely on the decision of the husbands. A study observed that about $34 \%$ of the husbands did not discuss with their wives prior to h.ıving a vasectomy (1984). Other studies revealed that decision about adoption of family planning is mainly taken by the males. But the females are responsible for managing and administering the contraceptives. The dilemma leads to the low acceptance rate of contraceptives (Hassan and Huq 1990)

The role of women in decision-making on sterilization (both vasectomy ad tubectomy was also investigated through the compensation pay ment study conducted in 1989 by NIPORT and the client salisfaction study carried out in $1999^{\circ}$. 
Figure 1: Some Features of Sterilization Decision-Making

\begin{tabular}{|l|c|c|c|c|c|c|c|c|}
\hline & \multicolumn{2}{|c|}{$\begin{array}{c}\text { Source of initial } \\
\text { information }\end{array}$} & \multicolumn{2}{|c|}{$\begin{array}{l}\text { Persons with home } \\
\text { discussed }\end{array}$} & \multicolumn{2}{|c|}{$\begin{array}{l}\text { Surce of most } \\
\text { iniormation }\end{array}$} & \multicolumn{2}{|c|}{$\begin{array}{l}\text { Greatest influence } \\
\text { on decision }\end{array}$} \\
\hline Tub. & Vas. & Tub. & Vas. & Tub. & Vas. & Tub. & Vas. & \\
\hline Spouse & 11 & 1 & 100 & 90 & 2 & 1 & 65 & 36 \\
Other family members & 1 & 2 & 43 & 8 & 2 & 1 & 2 & 0 \\
Relatjves/friends & 57 & 60 & 73 & 60 & 18 & 53 & 12 & 29 \\
F.P. workers & 17 & 17 & 51 & 40 & $? 7$ & 21 & 15 & 16 \\
NGO workers & 1 & 1 & 4 & 2 & 3 & 2 & 2 & 2 \\
Referres & 2 & 5 & 8 & 27 & 2 & 12 & 1 & 12 \\
Dais & 5 & 0 & 17 & 1 & 7 & 0 & 3 & 0 \\
Mass-media & 7 & 12 & - & - & 2 & 8 & 0 & 4 \\
Other & 1 & 2 & 1 & 2 & 2 & 1 & 0 & 1 \\
\hline Total & 100 & 100 & - & - & 100 & 100 & 100 & 100 \\
\hline
\end{tabular}

Sources: (i) Clinic-Based Survey of Sterilization Clients (1987)

(ii) Cleland and Mauldin (1987; p.27)

Both studies showed the males had the highest influence in deciding about the acceptance of sterilization. About 65 percent of women in the former study, and 34 percent women in the latter study reported that their husbands had the greatest influence on the decisions. Only a minority $(18 \%)$ of women but a larger proportion of men $(30 \%)$ identified a family planning worker or referrer as the person who had the greatest influence on their decision about sterilization.

Figure 2: Influence of persons/media in the decision-making process on Vasectomies and Tubectomies

\begin{tabular}{|l|c|c|}
\hline Persons/media having & Vasectomy $(\%)$ & Tubectomy $(\%)$ \\
\hline most influence & 15.3 & 34.2 \\
Husband/wife & 5.3 & 3.1 \\
Relatives & 16.4 & 2.2 \\
Neighbour & 1.0 & 0.3 \\
Dai/TBA & 53.3 & 49.9 \\
Family planning workers & 0.5 & 0.3 \\
Radio/TV/Newspaper & 8.0 & 10.0 \\
Others & & \\
\hline
\end{tabular}

Source : Client Satisfaction on Sterilization, 1990 
The Bangladesh Fertility Survey of 1989 measured women's autonomy using questions regarding their ability to travel alone, make decisions etc. The results showed that Bangladeshi women are still seriously constrained in their ability to make and implement decisions. Only a tiny percentage ( $10 \%$ or less) reported they could decide independently on such matters as children's schooling, visits to relatives, shopping, family planning and health treatment (Huq and Cleland 1990).

Focus group discussions were initiated in Bangladesh on the subject of women's rights. It was found that most women had little understanding of the issue. They considered, for example, that the husband is the best person to protect her rights and that women are less important than men in society. A few women expressed such views that if the husband did not behave properly, the woman's own family members would look after her rights. Only two of the women scid that they wanted their status to be improved, but they seemed completely ignorant about the process of improvement. Another woman said, "Don't say things like that, it may create more problems in the family." (Sabir 1993)

\section{THE IMPORTANCE OF FEMALE AUTONOMY WITHIN A FRAMEWORK OF CULTURAL DETERMINANTS OF CONTRACEPTIVE BEHAVIOR}

Several studies were undertaken to investigate the male's role and involvement in promoting women's participation in decision-making.

One of the pioneering studies in this regard states the following: Male involvement in contraception decision is seldom recognized in family planning programs, yet men's support or opposition has a strong impact on contraceptive use. The problem of male participation has at least four dimensions - biological, cultural, economical and technological. The fact that men are not personally involved in the problems and risks of pregnancy and child birth naturally makes them less responsible. Unlike women, men are fertile every day of the month and thus must take precautions at all times. Yet few traditional cultures expect the man to take the primary responsibility for contraception. Cultural and social barriers present possibly the greatest obstacle to instilling in men positive attitudes towards fertility control. In the majority of traditional societies, the status quo favours men as the dominant gender in all spheres except child care. The low economic status of women also works against their ability to gain their partners' cooperation to practice family planning. The current emphasis on female methods in most family planning programs also results from the fact that considerably more research has been conducted on the female reproductive system than on the male. Research on male methods has been less intensive and less successful (Gulhati, K, People. 1986; 13 (1) 3-4

Another study "Male Involvement in Family l'lanning: Program Initiatives Conducted by IPPF," found that the chief reason that emerges for the need to promote male involvement in family planning is that of fostering a better relationship between men and women through the practice of family planning as a jont and equal responsibility. This is, in fact, the underlying theme of the IPPF's overall concern in this particular area....... The lag may be attributed to the fact that family planning has been a female centered activity. As women are always the focus of contraceptive motivation and family planing programs, men gradually related the responsibility for such decisıon-making to women. It also found that 
the service delivery efforts in the various countries often fall under the categories of motivation for supporting women in their contraceptive decision-making and for acceptance of responsibility and sharing in family planning efforts and knowledge so that the men can be of better judges of their own potential welfare in an informed way.

Vasectomy - an International Appraisal by Johnson JH (1983), found that although an estimated 100 million couples who practice contraception have chosen sterilization as their accepted method, an overwhelming majority of the sterilizations were obtained by women even though the vasectomy is known to be simpler, safer and cheaper than tubal ligation.

Malawi's 1994 Family Formation Survey on "Arousing Malaw i's Men" indicated that most men were ready to support their wives' decisions to space birtlis, but in practice this was not the case.

Family for the Future runs similar in "Man to Man", a program inspired by similar efforts in Switzerland and intended to motivate men to support their women in seeking reproductive health and family planning services while themselves accepting some responsibility for contraception. Some 8,000 men from 20 corporations participated in the sessions during the program's recent pilot phase. Through "Man-to-Man," men are welcome at child spacing clinics, and this could lead to ready acceptance of male methods such as condoms and vasectomies. Men's reluctance to permit their women to seek child spacing occurs because in Malawi the child spacing program is run under maternal and child health care. The 8,000 men have taken 120,000 condoms. A recent evaluation suggests that $51 \%$ of these men are ready to use contraceptives; $49 \%$ would teach other men about contraception; $13 \%$ would allow their wives to attend child spacing clinics; another $14 \%$ have already done so. Of a sample of 200 men who have been through the program, $8 \%$ would consider having a vasectomy, $67 \%$ favoured tubal ligation for their wives, while $22 \%$ were against permanent methods. Neighboring clinics confirmed an increase in the number of women looking for child spacing because of a better appreciation of the subject by men.

The studies show both socio-economic and socio-cultur.1 factors are responsible for less participation of women in decision-making. A conceptual framework developed by Ahmed Al-Sabir and John Simons based on field studies in Bangladesh (1994) is presented in figure 3. In this conceptual famework, absolutism and individualism are seen as the underlying dimensions of relevant world views (Simons, 1986). Alssolutism refers to the degree to which behaviour is seen as subject to a religious doctrine that allows no compromise. Individualism refers to the extent to which the individual s rights and needs are given priority over the perceived expectations of the community. Variation on these dimensions (which is not directly measured) is seen as having implications for, and being implied by, variation in such dimensions as religiosity, female autonomy, and so on. Thus where world views are high in absolutism and low in individualism women are likely, in the circumstances of rural Bangladesh, to have little autonomy, to be socially secluded, to be religious and unworldly, to have a traditional attitude towards family size - that is, to prefer large families - and a negative attitude towards the use of contrace ption. More appropriately we can see the following conceptual framework to determine lactors associated in women's decision-making processes: 
Figure 3: Framework for the study of cultural determinants of contraceptive behavior in Bangladesh.

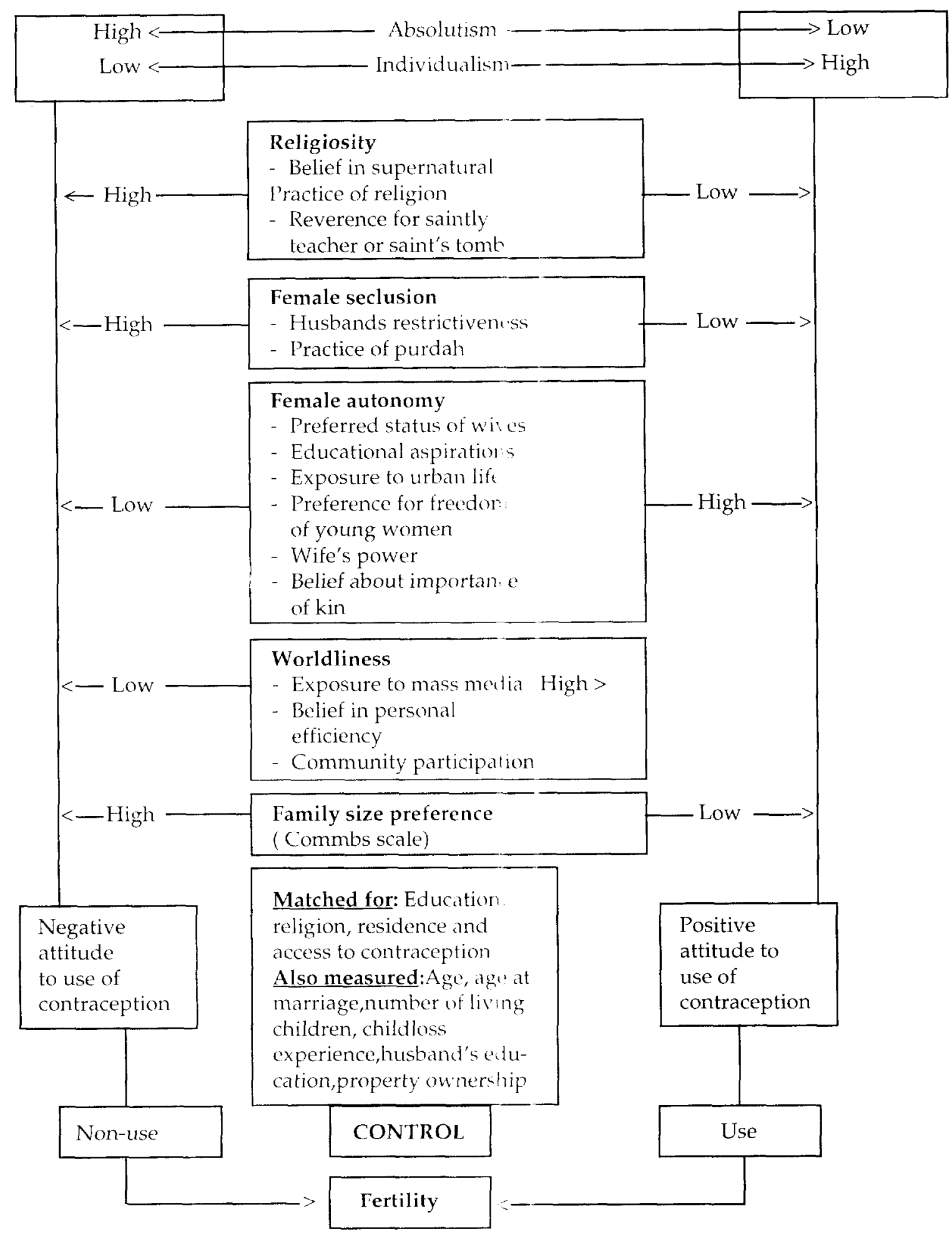


In Bangladesh the lower socio-economic conditions of the women don't allow them to participate actively in the decision-making of family affairs, particularly on reproductive matters and spacing their family size. So far, programs and research have focused mostly on the women. Very few research has been done and limited program interventions were carried out to promote male support for female autonomy.

\section{MALE MOTIVATION AND MALE INVOLVEMENT IN FAMILY PLANNING}

In Bangladesh, male involvement in family planning has taken the following forms: (1) males as users of contraceptives, (2) males supporting their wives in using contraceptives, (3) males as professional or para-professional providers of family planning information and services.

Until 1975, the overall level of contraceptive prevalence was low, with only $7.7 \%$ in 1975 (CPS 1975; NIPORT). Vasectomy demonstrated a relatively high acceptance rate in the mid 1960 s, but at present, its contribution to overall contraceptive prevalence is comparatively marginal. Acceptance of condoms has increased substantially; however, the utilisation of a relevant proportion of distributed condoms is unaccounted for ("condom gap"). Other papers presented at this workshop will provide more detailed information and analysis on use of male contraceptive methods.

Husbands' support to their wives for using family planning methods takes different forms, such as giving approval to using contraception, bringing contraceptives, providing information which may be more easily accessible to males due to their greater mobility. The impact of husband-wife communication on female contrac eptive continuation was investigated among 120 non-pregnant women of reproductive age. It showed that $96.7 \%$ of women among continuers and $88.3 \%$ among discontinuers said that their husbands supported their use of contraception. $93.3 \%$ of continuers and $98.3 \%$ of discontinuers reported that they talked to their husbands about contraception use. A significant corre lation was found between the variables of contraceptiv' use and motivation to avoid pregnancy among women who perceived that their husbands were supportive ( $\mathrm{p}<$ 0.001).(Chowdhury and Harvey 1991). However, little is known about the actual communication between husband and wife even in cases wher husbands support their wife's utilisation of family planning methods. Does it mean that wives are encouraged to actively participate in the decision making? Or does it mean that they are told by their husbands to prevent a pregnancy, what contraceptive method to use, etc.? How do the spouses actually arrive at a "joint decision"?

Family Planning Inspectors (FPIs) are the cadre of male family planning workers working at community level. While the FWAs are contacting the women in the household with few exception, male FPIs who are supervisors join hands with the FWAs in motivating and accompanying male clients, particularly vasectomy client $;$, to the VSC service points. FPIs are also responsible for group activities, social mobilization and media utilization within a union. As a local person, he is normally found to hold better influence over the male members of the community. He also mobilizes opinions of local leaders, teachers, officials, imams, NGOs and the like (Begum 1993). A recent sturly on the Family Planning Inspector (FPI) showed that a great majority of FPIs were involved in the IEM activities in some way or the other. During their participation in IEM activities, the FPIs were involved in creating awareness among the people to accept family planning through group discussions, 
followed by motivation work through displays of printed materials and then implementation of the film shows. It also showed that FPIs were involved in sterilization activities which included rendering pre and post-operative services, helping clients to undergo sterilization, motivating clients to undergo sterilization, informing FWAs about the time and place for arranging the sterilization camps and also visiting the operated patients and informing the doctors about the cor. plaints of the sterilized clients (Khan 1993).

\section{RECOMMENDATIONS FOR THE FUTURE}

\section{Gender Equality and Equity}

Gender means both women and men - in family planning the focus has been on women almost to the exclusion of men. We need to reduce/eliminate discrimination against women while also supporting men's roles in their own reproductive health and fertility as well as the health and well being of the spouse and family.

\section{Information, Education and Communication}

A major shift of the current IEC programs should take place. As a portrayal of the roles of men and women, boys and girls, the underlying principle should be to inform and educate, not "promote" or "motivate" so that people can choose and act. More education and information programs for encouraging men to take greater responsibility for family planning should be undertaken. Rather than promoting specific contraceptive methods, focus should be given on responsible parenthood and encourage men to either use contraceptives themselves or to support their partners in using a method.

\section{Training of Field Workers and Supervisors}

Training curricula of field workers and their supervisors should focus more on male motivation for family planning, and the promotion of women's active participation in decision-making for family planning. The FPI being the male community worker in family

planning should be motivated and enabled to work as a charge agent for promotion of women's participation in decision-making. 


\section{REFERENCES:}

1. Hassan SS; Huq N. Role of rural women in the family decision-making process with special reference to acceptance of family planning Dhaka: NIPORT, 1990.

2. Ahmad S; Islam N; Rahman S. I'he client satisfaction with sterilization procedure. Dhaka: RTA, 1990.

3. HuqN; AhmadS. Study of compensation payments.ınd family planning in Bangladesh: a synthesis. Dhaka: NIPORT, 1989.

4. Sabir AA. Cultural influences on contraceptive behavior in rural Bangladesh: a doctoral thesis. Dhaka: NIPOR'I', 1993.

5. Sabir AA and Simons J. Worldliness and fertility control: cultural attributes of contraceptive users among women in rural Bangladesh, paper presented in a seminar on Values and Fertility Change, Switzerland, 1994

6. Simons J. Culture, Economy and Reproduction in Contemporary Europe. Edit by Coleman, D. and Schofield, R. The State of Population Theory. Oxford: Blackwell. 1986.

7. Huq N; Cleland J. Bangladesh Fertility Survey 1989. Dhaka: NIPORT, 1990.

8. Begum S. Factors influencing the acceptability of vasec tomy among Bangladesh men. Paper presented in the workshop on male participation in family planning, Lahore, Pakistan, June 7-9, 1993.

9. Khan A. R. et al.: Evaluation of Performance of the F.rmily Planning Inspectors and Health Assistants. Dhaka 1993. 